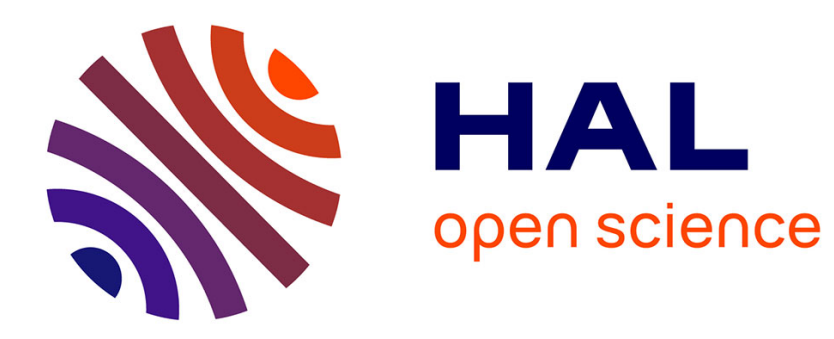

\title{
Deregulation shock in product market and unemployment
}

Luisito Bertinelli, Olivier Cardi, Partha Sen

\section{To cite this version:}

Luisito Bertinelli, Olivier Cardi, Partha Sen. Deregulation shock in product market and unemployment. 2011. hal-00589228

\section{HAL Id: hal-00589228 \\ https://hal.science/hal-00589228}

Preprint submitted on 28 Apr 2011

HAL is a multi-disciplinary open access archive for the deposit and dissemination of scientific research documents, whether they are published or not. The documents may come from teaching and research institutions in France or abroad, or from public or private research centers.
L'archive ouverte pluridisciplinaire HAL, est destinée au dépôt et à la diffusion de documents scientifiques de niveau recherche, publiés ou non, émanant des établissements d'enseignement et de recherche français ou étrangers, des laboratoires publics ou privés. 


\title{
ECOLE POLYTECHNIQUE
}

\section{DEREGULATION SHOCK IN PRODUCT MARKET AND UNEMPLOYMENT}

\author{
Luisito BERTINELLI \\ Olivier CARDI \\ Partha SEN
}

April 2011

Cahier $n^{\circ}$ 2011-10

\section{DEPARTEMENT D'ECONOMIE}

Route de Saclay

91128 PALAISEAU CEDEX

(33) 169333033

http://www.economie.polytechnique.edu/

mailto:chantal.poujouly@polytechnique.edu 


\title{
DEREGULATION SHOCK IN PRODUCT MARKET AND UNEMPLOYMENT *
}

\author{
Luisito BERTINELLI \\ University of Luxembourg CREA
}

\author{
Olivier CARDI \\ University Panthéon-Assas ERMES \\ Ecole Polytechnique
}

\author{
Partha SEN \\ Delhi School of Economics
}

\begin{abstract}
In a dynamic general equilibrium model with endogenous markups and labor market frictions, we investigate the effects of increased product market competition. Unlike most macroeconomic models of search, we endogenize the labor supply along the extensive margin. We show that beneficial effects in labor market outcomes require that the condition for saddle-path stability must be fulfilled whereas instability yields detrimental effects. Additionally, we find numerically that most of the decline in the unemployment rate can be attributed to the increase in the labor force, while the number of job seekers remains fairly unchanged. For a calibration capturing alternatively European and the U.S. labor markets, a deregulation episode, which lowers the markup by 3 percentage points, results in a fall in the unemployment rate by 0.1 and 0.05 percentage point, respectively, while the labor share is almost unaffected in the long-run.
\end{abstract}

Keywords: Imperfect competition; Endogenous markup; Search theory; Unemployment; Deregulation.

JEL Classification: E24; J63; L16.

\footnotetext{
* Constructive comments by Michel Beine, Andreas Irmen, Simone Moriconi, Pierre Picard, Henri Sneessens, and Eric Strobl are gratefully acknowledged. An earlier version of this paper was presented to the 14th Conference Theories and Methods of Macroeconomics, 17-18th March 2010 and has benefited very helpful comments of the participants. Of course the usual disclaimers apply. Corresponding author: Luisito Bertinelli. Address correspondence: Luisito Bertinelli, Department of Law, Economics and Finance. 162 A, avenue de la Faïencerie, L-1511 Luxembourg. Phone: +352466644 6620. Fax: +352466644 6633. E-mail: luisito.bertinelli@uni.lu. Address correspondence: Olivier Cardi, Université Panthéon-Assas Paris 2, ERMES, 12 Place du Panthéon, 75230 Paris Cedex 05. France. Phone: +33144418973. Fax: +331 405181 30. E-mail: olivier.cardi@u-paris2.fr. Address correspondence: Partha Sen, Delhi School of Economics, Delhi University, Delhi 110007, India, Phone: (91)-11-27666534 Fax: (91)-11-27667159. E-mail: partha@econdse.org.
} 


\section{Introduction}

The role of product market reforms in achieving the objective of lower unemployment rate has recently received a lot of attention amongst policy makers and academics. While the empirical literature finds that poor competition in product markets could be a cause of the poor performance of European labor markets, the connection between product market regulation and unemployment has received very little attention from the dynamic general equilibrium literature, except Ebell and Haefke [2009]. ${ }^{1}$ In particular, the relationship between product market competition and equilibrium unemployment has been studied by considering a static framework thus abstracting from dynamic effects (see Blanchard and Giavazzi [2003], Spector [2004]). As Ebell and Haefke [2009], we use a dynamic general equilibrium model to quantify the unemployment effect of regulation in goods market. In contrast to Ebell and Heaefke, we endogenize labor supply along the extensive margin (i.e., the labor force participation decision) and analyze both the dynamic and steady-state effects analytically. Importantly, we derive the condition for saddle-path stability and show that detrimental effects on labor market outcomes may emerge as a consequence of dynamic instability.

There exists a growing body of empirical evidence to support the positive relationship between product market regulation and the performance of labor markets. At a micro level, Bertrand and Kramarz [2002] find that French regions which restricted entry (into retailing) experienced slower rates of job growth. At a macro level, estimates by Bassanini and Duval [2006] show that stringent anti-competitive product market regulation raises aggregate unemployment, though the impact is much smaller than a reduction in unemployment benefits or in the tax wedge. Griffith et al. [2007] provide evidence that the product market deregulation experienced in the 1990s by some OECD countries was associated with a decline in the unemployment rate, particularly in countries with a higher workers' bargaining power. According to their findings, a fall of 3 percentage points of the price-cost margin will generate a decrease in the unemployment rate ranging between 0.6 and 1.1 percentage points as the bargaining coverage (capturing the worker bargaining power) increases from $53 \%$ to $97 \%$.

To explore the dynamic link between product market regulation and unemployment, we develop a novel framework combining imperfect competition in product markets and unemployment in the labor market. We see our setup as an extension of the framework by Heijdra and Ligthart [2009] who solve analytically a dynamic open economy model with search unemployment and endogenous labor force participation. ${ }^{2}$ In the tradition of Diamond-Mortensen-

\footnotetext{
${ }^{1}$ Bilbiie, Ghironi and Melitz [2010] analyze the effect of a deregulation shock within a dynamic general equilibrium model with entry and exit of firms but they abstract from labor market frictions.

${ }^{2}$ Our framework also builds upon Merz [1995], Andolfatto [1996], Shi and Wen [1999] who construct dynamic
} 
Pissarides, unemployment arises because it takes time for firms to hire workers and for unemployed workers to find a job. Because firms face a cost by maintaining job vacancies, they receive a surplus equal to the markup-adjusted marginal product of labor less the product wage. Symmetrically, so as to compensate for the cost of searching for a job, unemployed workers receive a surplus equal to the product wage less the reservation wage. Nash bargaining between firms and workers yields a product wage defined as the weighted sum of the marginal product of labor and a reservation wage. As Heijdra and Ligthart, we depart from the usual practice by assuming endogenous labor force participation which implies that the reservation wage varies over time. In contrast to Heijdra and Ligthart who assume perfect competition in product markets, we consider monopolistic competition. Building on Jaimovich and Floetotto [2008], we assume that only a limited number of intermediate good producers operate within each sector, so that the price-elasticity of demand and thereby the markup faced by each firm depends on the number of competitors. ${ }^{3}$ The markup variation is central to the propagation mechanism of a deregulation shock.

We contribute to the product market regulation literature in four respects. First, our setup can be solved analytically and delivers simple formulas which illuminate the role of labor market institutions in driving the effects of a deregulation episode. Our second contribution is more technical and relates the stability of the dynamic system to the beneficial effects on labor market outcomes. Third, we are able to depict the transitional adjustment of key variables by using simple phase diagrams. Finally, we also provide a novel quantitative exploration, in particular by estimating the size of the short and long-term effects of a deregulation episode. We detail below our four contributions.

While using a fully dynamic general equilibrium model, our setup yields simple formulas which provide predictions related to the role of labor market variables in determining the size of the effects of a deregulation shock in product markets. In particular, we find that a deregulation shock lowers unemployment more as labor supply at the extensive margin is larger, unemployment benefits are smaller, the workers' bargaining power is higher, and the product markets are initially not very competitive. Importantly, the combined effect of endogenous labor force participation, which has been so far ignored by the literature, and endogenous markups triggers a multiplicative employment effect. The reason is that as more

\footnotetext{
general equilibrium models with labor markets characterized by search frictions. We depart from these papers by solving the model analytically and introducing endogenous markups.

${ }^{3}$ See e.g., Wu and Zhang [2000] and Zhang [2007] who develop dynamic general equilibrium models with monopolistic competition and free entry, in which price elasticity of demand at firm level (evaluated at symmetric equilibria) is proportional to the number of firms in the industry. In contrast to us, they abstract from imperfect labor markets.
} 
agents participate in the labor market, employment increases further. As a consequence, the markup falls by a larger amount which raises labor demand and thereby labor market tightness. Hence, the reservation wage rises more which increases further the labor force participation and thereby employment.

Our dynamic model is tractable enough to derive analytically the condition for saddlepoint stability and to fully characterize transitional dynamics. Additionally, we show that long-term effects on labor market variables crucially depend on the local stability properties of the dynamical system. If the long-run equilibrium is saddle-path, improving competitive conditions yields beneficial effects on labor market outcomes. Importantly, we find that instability arises when product markets are initially too much regulated. In this case, enhanced competition lowers employment and raises the unemployment rate in the long-run.

In contrast to Heijdra and Lightart [2009], the introduction of endogenous markups restores transitional dynamics for labor market variables. Moreover, we are able to derive analytically the dynamics and illustrate the transitional adjustment by using phase diagrams. In particular, employment and labor market tightness co-vary, while employment and the unemployment rate vary in opposite direction. Interestingly, the unemployment rate unambiguously increases on impact as more agents search for a job and employment is initially predetermined.

While the model can be solved analytically, we propose some numerical simulations to illustrate key theoretical results and discuss policy implications. In the same spirit as Ebell and Haefke [2009], we investigate to which extent product market competition decreases unemployment and increases wages. In this regard, we offer two calibrations of the model, one aimed at capturing the United States, the other aimed at capturing Europe with its more "rigid" labor market. Since data show considerable heterogeneity across European Union members, we conduct a sensitivity analysis with respect to pivotal parameters capturing the regulation of goods and labor markets. In contrast to Ebel and Haefke [2009] who calibrate their model to quantify the extent to which the poor performance of European labor markets relative to the U.S. can be attributed to lower competition, we compare the size of the decline of the unemployment rate in Europe and the U.S. after a deregulation shock of the same magnitude. To do so, we use panel data for 16 OECD countries over the period 1985-2003. Our estimates show that when the OECD regulatory index falls by one unit, the subsequent decline in the markup falls in the range between 2.8 and 3.3 percentage points. Considering a fall in fixed costs which lowers the markup by 3 percentage points, we find that such a deregulation episode lowers the unemployment rate by about 0.1 percentage point and raises 
the Nash bargaining wage by $2.2 \%$ for the Europe baseline calibration. These effects increase substantially in countries with higher worker bargaining power, initial poorly competitive product markets, or larger elasticity of labor supply at the extensive margin. When the labor market parameters are chosen so as to match the U.S. economy, it is found that beneficial effects on labor market outcomes are mitigated.

Finally, as in Blanchard and Giavazzi [2003], we investigate the distribution effect between labor income and profits triggered by a deregulation episode. We find numerically that the labor share does not decrease, regardless of the scenario or time horizon. However, whereas the short-run rise in the labor share falls in the range between 0.2 and 1.5 percentage points of GDP, the long-term effects are almost insignificant.

The remainder of the paper is organized as follows. In section 2, we develop an open economy model with endogenous markup stemming from a limited number of competitors within each industry and unemployment arising from matching frictions. Section 3 analyzes equilibrium dynamics and steady-state. Section 4 provides an analytical exploration of the transmission of a deregulation shock. In Section 5, we report results from numerical simulations and discuss the role of labor and product market parameters. Section 6 summarizes our main results and concludes.

\section{The Framework}

We look at a small open economy which faces a given world interest rate, $r^{\star}$ and is populated by a constant number of identical households and firms that have perfect foresight and live forever. Households decide on labor market participation and consumption while firms decide on hours worked. The economy contains a large number of sectors. Within each sector, there are a limited number of monopolistically competitive intermediate firms who produce differentiated goods. Hence, within a given sector, the price-elasticity of demand faced by each firm depends on the number of competitors, which results in an endogenous markup. Each firm produces a unique variety by renting labor services from an employment agency. The labor market, in the tradition of Diamond-Mortensen-Pissarides, consists of a matching process between the employment agency who posts job vacancies and unemployed workers who search for a job. Finally, differentiated goods are aggregated into a sectoral good and a perfectly competitive firm aggregates sectoral goods to produce a final good. The final good can be exported or consumed domestically, or can cover both fixed cost and cost of recruiting. ${ }^{4}$

\footnotetext{
${ }^{4}$ More details on the model as well as the derivations of the results which are stated below are provided in a Technical Appendix which is available on request.
} 


\section{$2.1 \quad$ Households}

The economy that we consider consists of a representative household with a measure one continuum of identical infinitely lived members. At any instant, members in the household derive utility from consumption goods $C$ and experience disutility from working and searching efforts. More precisely, the representative household comprises members who engage in only one of the following activities: working, searching a job, or enjoying leisure. Assuming that the representative individual is endowed with one unit of time, leisure is defined as $l \equiv 1-L-U$, where $L$ denotes units of labor time and $U$ corresponds to time spent on searching for a job. Hence, the labor force is not constant which enables us to focus on both the transition between employment and unemployment on the one hand, and the transition between leisure and labor force on the other. Unemployed agents are randomly matched with job vacancies according to a matching function described later. Since the timing of a match is random, agents face idiosyncratic risks. To simplify the analysis, we assume that members in the household perfectly insure each other against variations in labor income. The representative household chooses the time path of consumption and labor force to maximize the following objective function: ${ }^{5}$

$$
\Upsilon(t)=\int_{0}^{\infty}[\log X(t)] e^{-\rho t} \mathrm{~d} t, \quad X \equiv C-\frac{L_{P}^{1+1 / \sigma_{L}}}{1+1 / \sigma_{L}}
$$

with $\rho$ the consumer's subjective time discount rate. For later use, we denote by $u$ the unemployment rate defined as $u=\frac{U}{U+L}=\frac{U}{L_{P}}$ with $L_{P}=L+U$ the labor force.

At each instant of time, $m U$ unemployed agents find a job and $s L$ employed individuals lose their job. Employment evolves gradually according to:

$$
\dot{L}(t)=m U(t)-s L(t)
$$

where $m$ denotes the rate at which unemployed agents find jobs and $s$ is the constant rate of job separation; $1 / m$ can be interpreted as the average unemployment duration; $m$ is a function of labor market tightness $\theta$ which is defined as the ratio of the number of job vacancies over unemployed agents in the economy.

Households supply $L(t)$ units of labor services for which they receive the product wage $w(t)$. They accumulate internationally traded bonds, $B(t)$, that yield net interest rate earnings $r^{\star} B(t)$. We denote by $A(t)$ the stock of financial wealth held by households which comprises the shadow value of employment defined later. Denoting by $T$ the lump-sum taxes, the flow

\footnotetext{
${ }^{5}$ Following Greenwood et al. [1988], the sub-utility functional form is specified so as to eliminate the wealth effect in the household's labor force participation decision.
} 
budget constraint is equal to households' real disposable income less consumption expenditure $C$ :

$$
\dot{A}(t)=r^{\star} A(t)+w(t) L(t)+B^{U} U(t)-T(t)-C(t),
$$

where $B^{U}$ represents unemployment benefits received by job seekers.

The representative household selects consumption, time dedicated for searching a job, and financial wealth:

$$
\begin{gathered}
\frac{1}{X}=\lambda, \\
L_{P}^{1 / \sigma_{L}}=m(\theta) \xi+B^{U}, \\
\dot{\lambda}=\lambda\left(\rho-r^{\star}\right), \\
\dot{\xi}=\left(s+r^{\star}\right) \xi-\left[v_{L_{P}}+w\right],
\end{gathered}
$$

where $\lambda$ and $\xi$ denote the shadow prices of wealth and finding a job, respectively. Eq. (4b) asserts that the opportunity cost of search to be equal to the marginal benefit of search where the quantity $L_{P}^{1 / \sigma_{L}}$ can be viewed as being the worker's reservation wage.

Equation (4a) can be solved for consumption:

$$
C=C(\bar{\lambda}, L, U)
$$

with $C_{L}=C_{U}=L_{P}^{1 / \sigma_{L}}>0, C_{\bar{\lambda}}=-X / \lambda<0$. Finally, we require the time preference rate $\rho$ to be equal to the world interest rate $r^{\star}$ in order to generate an interior solution. This standard assumption in an open economy setting implies that the marginal utility of wealth, $\lambda$, must remain constant over time, i. e. $\lambda=\bar{\lambda}$.

\section{$2.2 \quad$ Firms}

Final output, $Y$, is produced in a competitive retail sector using a constant-returns-to-scale production function which aggregates a measure one continuum of sectoral goods:

$$
Y=\left[\int_{0}^{1}\left(\mathcal{Q}_{j}\right)^{\frac{\omega-1}{\omega}} \mathrm{d} j\right]^{\frac{\omega}{\omega-1}},
$$

where $\omega>0$ represents the elasticity of substitution between any two different sectoral goods and $\mathcal{Q}_{j}$ stands for intermediate consumption of sector $j$ variety. The final good producers behave competitively, and the households use the final good for consumption.

Denoting by $P$ the price of the final output and $\mathcal{P}_{j}$ the price of the $j$ th sectoral good, the profit of the final good producer is given by:

$$
\pi^{F}=P\left[\int_{0}^{1}\left(\mathcal{Q}_{j}\right)^{\frac{\omega-1}{\omega}} \mathrm{d} j\right]^{\frac{\omega}{\omega-1}}-\int_{0}^{1} \mathcal{P}_{j} \mathcal{Q}_{j} \mathrm{~d} j .
$$


Solving the maximization problem, we obtain the demand for each intermediate input:

$$
\mathcal{Q}_{j}=\left(\frac{\mathcal{P}_{j}}{P}\right)^{-\epsilon} Y
$$

where the price of the final output is given by:

$$
P=\left(\int_{0}^{1} \mathcal{P}_{j}^{1-\epsilon} \mathrm{d} j\right)^{\frac{1}{1-\epsilon}} .
$$

In each of the $j$ sectors, there are $N>1$ firms producing differentiated goods that are aggregated into a sectoral good by a CES aggregating function. The output of sectoral good $j$ is given by: ${ }^{6}$

$$
\mathcal{Q}_{j}=N^{-\frac{1}{\epsilon-1}}\left[\int_{0}^{N}\left(\mathcal{X}_{i, j}\right)^{\frac{\epsilon-1}{\epsilon}} \mathrm{d} i\right]^{\frac{\epsilon}{\epsilon-1}},
$$

where $\mathcal{X}_{i, j}$ stands for output of firm $i$ in sector $j$ and $\epsilon$ is the elasticity of substitution between any two varieties.

Denoting by $\mathcal{P}_{i, j}$ the price of good $i$ in sector $j$, the profit function for the jth sector good producer denoted by $\pi_{j}^{S}$ is:

$$
\pi_{j}^{S}=\mathcal{P}_{j} N^{-\frac{1}{\epsilon-1}}\left(\int_{0}^{N}\left(\mathcal{X}_{i, j}\right)^{\frac{\epsilon-1}{\epsilon}} \mathrm{d} i\right)^{\frac{\epsilon}{\epsilon-1}}-\int_{0}^{N} \mathcal{P}_{i, j} \mathcal{X}_{i, j} \mathrm{~d} i .
$$

The demand faced by each producer $\mathcal{X}_{i, j}$ is:

$$
\mathcal{X}_{i, j}=\left(\frac{\mathcal{P}_{i, j}}{\mathcal{P}_{j}}\right)^{-\epsilon} \frac{\mathcal{Q}_{j}}{N}
$$

and the price index of sector $j$ is given by:

$$
\mathcal{P}_{j}=N^{-\frac{1}{1-\epsilon}}\left(\int_{0}^{N} \mathcal{P}_{i, j}^{1-\epsilon} \mathrm{d} i\right)^{\frac{1}{1-\epsilon}} .
$$

Combining (8) and (12), the demand for variety $\mathcal{X}_{i, j}$ can be expressed in terms of the relative price of the final good:

$$
\mathcal{X}_{i, j}=\left(\frac{\mathcal{P}_{i, j}}{\mathcal{P}_{j}}\right)^{-\epsilon}\left(\frac{\mathcal{P}_{j}}{P}\right)^{-\omega} \frac{Y}{N} .
$$

Intermediate output $\mathcal{X}_{i, j}$ is produced using labor $\mathcal{L}_{i, j}$ :

$$
\mathcal{X}_{i, j}=\mathcal{L}_{i, j}
$$

As it is common in the literature, we assume that the production function is linear in labor. ${ }^{7}$

\footnotetext{
${ }^{6}$ By having the term $N^{-\frac{1}{\epsilon-1}}$ in $(10)$, the analysis abstracts from the variety effect and concentrates solely on the effects of markup variation.

${ }^{7}$ We discuss the implications of decreasing returns to scale in labor for steady-state changes in a Technical Appendix available from the authors. We find that our results remain unchanged qualitatively.
} 
To avoid an interaction between hiring costs and market power, we break up the hiring decision by assuming that each intermediate producer uses labor services at a cost $\mathrm{W}$ paid to an employment agency which negotiates wages at a rate $w$ with the new hires. ${ }^{8}$ As intermediate good producers face a labor cost $\mathrm{W}$ per employee, the profit function of the intermediate good producer $i$ in sector $j$ denoted by $\pi_{i, j}^{P}$ is:

$$
\pi_{i, j}^{P}=\mathcal{P}_{i, j} \mathcal{L}_{i, j}-\mathrm{W} \mathcal{L}_{i, j}-P \varphi
$$

where $\varphi$ corresponds to fixed costs measured in terms of the final good. Denoting by $e$ the price-elasticity of demand and by $\mu$ the mark-up with $\mu \equiv \frac{e}{e-1}$, the first-order condition reads:

$$
\mathcal{P}_{i, j} \frac{1}{\mu}=\mathrm{W}
$$

We consider a symmetric equilibrium where all firms in the intermediate good sector produce the output level $\mathcal{X}_{i, j}=\mathcal{X}$ with the same quantity of labor $\mathcal{L}_{i, j}=\mathcal{L}$, set the same price $\mathcal{P}_{i, j}=\mathcal{P}$, and have the same gross profits $\pi_{i, j}^{P}=\pi^{P}$. Considering the final good as the numeraire and normalizing its price to one, we have $\mathcal{P}=P=1$. In equilibrium, eq. (17) rewrites as:

$$
\frac{1}{\mu}=\mathrm{W}
$$

According to the Dixit and Stiglitz [1977] assumption, the number of competitors is large enough within each sector to yield a fixed price-elasticity of demand. Yet, as emphasized by Yang and Heijdra [1993], this assumption is an approximation when the final good is aggregated by a finite number of intermediate goods. We depart from the usual practice, following Galí [1995], in assuming that the number of firms is large enough so that we can ignore the strategic effects but not so large that the effect of entry is minuscule on the firm's demand curve. Consequently, the price elasticity of demand faced by a single firm is no longer constant and equal to the elasticity of substitution between any two varieties, but rather a function of the number of firms $N$. Taking into account that output of one variety does not affect the general price index $P$, but influences the sectoral price level, in a symmetric equilibrium, the resulting price elasticity of demand is: ${ }^{9}$

$$
e(N)=\epsilon-\frac{(\epsilon-\omega)}{N}, \quad N \in(1, \infty) .
$$

Assuming that $\epsilon>\omega$ (see Jaimovich and Floetotto [2008]), the price elasticity of demand faced by one single firm is an increasing function of the number of firms $N$ within a sector.

\footnotetext{
${ }^{8}$ Hence, each intermediate good producer acts as a seller in a monopolistically competitive market while in the labor market, it rents labor services from an employment agency which posts vacancies to hire workers. This allows us to keep the surplus from the hiring decision separate from the profits of a firm (that signal entry into the industry).

${ }^{9}$ Details of derivation can be found in the Technical Appendix.
} 
Henceforth, the markup $\mu=\frac{e}{e-1}$ decreases as the number of competitors increases, i.e. $\mu_{N}<$ 0.

\subsection{Hiring}

We assume that an employment agency is aimed at posting vacancies and hiring workers. This employment agency receives the markup adjusted marginal product of labor and pays the wage $w$ decided by the generalized Nash bargaining solution. The human resource agency maintains job vacancies $V$ to hire workers, at a cost per vacancy $\kappa$ which is assumed to be constant and measured in terms of the final good (with $P=1$ ). The profit of the employment agency denoted by $\Pi^{H}$ is:

$$
\Pi^{H} \equiv \mathrm{W} L-w L-\kappa V
$$

where $L$ is aggregate labor, i.e. $L=n \mathcal{L}$. Denoting by $f$ the rate at which a vacancy is matched with unemployed agents, the law of motion for aggregate labor is given by:

$$
\dot{L}=f(\theta) V-s L
$$

where $f V$ represents the flow of job vacancies which are fulfilled; $f$ decreases with labor tightness $\theta$.

Denoting by $\gamma$ the shadow price of employment to the employment agency, and keeping in mind that $f$ is taken as given, the maximization problem yields the following first-order conditions:

$$
\begin{aligned}
\gamma & =\frac{\kappa}{f(\theta)} \\
\dot{\gamma} & =\gamma\left(r^{\star}+s\right)-(\mathrm{W}-w) .
\end{aligned}
$$

Eq. (22a) requires the marginal cost of vacancy, $\kappa$, to be equal to the marginal benefit of vacancy, $f(.) \gamma$. Solving equation (22b) forward and invoking the transversality condition yields:

$$
\left.\gamma(t)=\int_{t}^{\infty}\left[\frac{1}{\mu}-w(\tau)\right)\right] e^{\left(s+r^{\star}\right)(t-\tau)} \mathrm{d} \tau
$$

Eq. (23) states that $\gamma$ is equal to the present value of the cash flow $\frac{1}{\mu}-w$ discounted at a rate $s+r^{\star}$.

\subsection{Matching and Wage Determination}

We now set the matching function and the wage determination scheme. As it is common in the literature, the matching function is assumed to take a Cobb-Douglas form:

$$
M(V, U)=M_{0} V^{\alpha_{V}} U^{1-\alpha_{V}}, \quad \alpha_{V} \in(0,1),
$$


where $M$ describes the number of job matches and $\alpha_{V}$ represents the elasticity of vacancies in job matches. We express the number of labor contracts per unemployment units:

$$
m=m(\theta)=M_{0} \theta^{\alpha_{V}}, \quad f=f(\theta)=\frac{m(\theta)}{\theta}=M_{0} \theta^{\alpha_{V}-1},
$$

with

$$
\frac{f^{\prime} \theta}{f}=-\left(1-\alpha_{V}\right), \quad \frac{m^{\prime} \theta}{m}=\alpha_{V}
$$

When a vacancy and a job-seeking worker meet, a rent is created which is equal to $\xi+\gamma$, where $\xi$ is the value of an additional job and $\gamma$ is the value of an additional worker. The division of the rent between the worker and employment agency is determined by generalized Nash bargaining over the wage rate:

$$
\max _{w}(\xi)^{\alpha_{W}}(\gamma)^{1-\alpha_{W}}, \quad \alpha_{W} \in(0,1)
$$

where $\alpha_{W}$ and $1-\alpha_{W}$ correspond to the bargaining power of the worker and the firm, respectively.

Solving for (27), the product wage $w$ is defined as a weighted sum of the markup-adjusted labor marginal product and the reservation wage:

$$
w=\alpha_{W} \frac{1}{\mu}+\left(1-\alpha_{W}\right) L_{P}^{1 / \sigma_{L}}
$$

A fall in the markup, which exerts an upward pressure on labor demand (see eq. (18)), or a rise in the labor market tightness, by raising the reservation wage (see eq. (4b)), pushes up the product wage.

\subsection{Free Entry and the Number of Firms}

In investigating the effects of deregulation in product markets, we impose the simplifying assumption of static entry decisions. This assumption is made to ensure almost closed form solutions and the derivation of easily interpretable expressions. ${ }^{10}$

Since at each instant, new intermediate good producers may enter and produce a new variety, each intermediate-good producer makes zero-profit. The zero-profit condition determines the number of firms:

$$
N=\frac{L}{\varphi}\left[1-\frac{1}{\mu(N)}\right]
$$

\footnotetext{
${ }^{10}$ We assume instantaneous entry to keep analytical tractability. In a Technical Appendix available on request from the authors, we show that introducing a cost of entry does not modify our main results. Additionally, because transitional dynamics cannot be analyzed analytically, we assume instantaneous entry which allows us to study the transitional adjustment by using phase diagrams.
} 
where $L$ is aggregate stock of employment which is equal to aggregate output, i.e. $Y=L$. The zero profit condition can be solved for the number of intermediate producers:

$$
N=N(L, \varphi)
$$

where $N_{L}>0, N_{\varphi}<0$. A rise in employment lowers the average cost which provides an incentive for firms to enter the market. By contrast, an increase in fixed costs reduces the number of firms by reducing profit opportunities.

Finally, summing profits in the intermediary producer sector and of the employment agency, we have:

$$
\Pi=N \pi^{P}+\Pi^{H}=L-w L-\kappa V-N \varphi,
$$

where $L-N \varphi=L / \mu(N)$. As it shall become clear later, this relationship will be useful when analyzing the behavior of the labor share.

\subsection{Government}

The final agent in the economy is the government. Unemployed benefits $B^{U} U$ are covered by lump-sum taxes $T$ according to the following balanced budget constraint:

$$
B^{U} U=T
$$

where we abstract from government spending for simplicity. ${ }^{11}$

\section{Solving the Model}

In this section, we characterize the equilibrium dynamics and then discuss the steady-state.

\subsection{Saddle-Path Stability}

In this subsection, we analyze saddle-path stability; hence, we first derive the system of differential equations.

\section{Linearized System}

Differentiating first (4b) w. r. t. time and substituting (4d) yields the dynamic equation for job seekers:

$$
\frac{1}{\sigma_{L}}\left(L_{P}\right)^{\frac{1}{\sigma_{L}}-1} \dot{U}=\left(L_{P}^{1 / \sigma_{L}}-B_{U}\right)\left[\left(s+r^{\star}\right)+\alpha_{V} \frac{\dot{\theta}}{\theta}\right]-m(\theta)\left(w-L_{P}^{1 / \sigma_{L}}\right)-\frac{1}{\sigma_{L}}\left(L_{P}\right)^{\frac{1}{\sigma_{L}}-1} \dot{L}
$$

\footnotetext{
${ }^{11}$ Government spending $G$ is considered in the numerical analysis for calibration purpose. Hence, eq. (32) rewrites as $B^{U} U+G=T$.
} 
where we used the fact that $m(\theta) \xi=\left(L_{P}^{1 / \sigma_{L}}-B_{U}\right)$.

Differentiating eq. (22a) w. r. t. time, substituting into eq. (22b), and eliminating $\gamma$ by using (22a), yields the dynamic equation for labor market tightness $\theta$ :

$$
\dot{\theta}(t)=\frac{\theta(t)}{\left(1-\alpha_{V}\right)}\left\{\left(s+r^{\star}\right)-\frac{f(\theta)\left(1-\alpha_{W}\right)}{\kappa} \Psi\right\},
$$

where $\Psi$ is the rent created when a job vacancy and a job-seeking worker meet, and is defined as

$$
\Psi \equiv \Psi(L(t), U(t), \varphi)=\frac{1}{\mu(N(t))}-(L(t)+U(t))^{1 / \sigma_{L}} .
$$

Linearizing in the neighborhood of the steady-state, and denoting steady-state values with a tilde, the dynamic system which comprises three equations, i.e. the accumulation equation for employment (2), the dynamic equation for labor market tightness (34) and the dynamic equation for job seekers (33), writes in matrix form:

$$
(\dot{L}, \dot{\theta}, \dot{U})^{T}=J(L(t)-\tilde{L}, \theta(t)-\tilde{\theta}, U(t)-\tilde{U})^{T},
$$

where the Jacobian matrix $J$ is given by:

$$
J \equiv\left(\begin{array}{ccc}
-s & m^{\prime} \tilde{U} & m(\tilde{\theta}) \\
-\frac{1-\alpha_{W}}{1-\alpha_{V}} \frac{\tilde{m}}{\kappa} \tilde{\Psi}_{L} & \left(s+r^{\star}\right) & -\frac{1-\alpha_{W}}{1-\alpha_{V}} \frac{\tilde{m}}{\kappa} \tilde{\Psi}_{U} \\
\left(2 s+r^{\star}\right)+\frac{\alpha_{W} \tilde{m} \tilde{\Psi}_{L}}{1-\alpha_{V}} \frac{\tilde{L}_{P} \sigma_{L}}{\left(\tilde{L}_{P}\right)^{1 / \sigma_{L}}} & -m^{\prime} \tilde{U} & \left(s+r^{\star}\right)-\tilde{m}+\frac{\alpha_{W} \tilde{m}}{1-\alpha_{V}}
\end{array}\right) .
$$

For analytical simplicity, we assume that the Hosios condition holds, i. e. $\alpha_{V}=1-\alpha_{W}$. Under these assumptions, the Trace and Determinant of the Jacobian matrix are ${ }^{12}$

$$
\begin{aligned}
\operatorname{Tr} \mathrm{J} & =\left(s+r^{\star}\right)+r^{\star}, \\
\operatorname{Det} \mathrm{J} & =-(s+\tilde{m})\left(s+r^{\star}\right)^{2}\left\{\frac{\left(s+\tilde{m}+r^{\star}\right)}{\left(s+r^{\star}\right)}+\frac{\eta_{\mu, N} \eta_{N, L}}{\mu} \frac{\left(\alpha_{V} \tilde{u}+\sigma_{L} \tilde{\chi}\right)}{\left(1-\alpha_{V}\right) \tilde{\Psi}}\right\} \lessgtr 0,
\end{aligned}
$$

where $\tilde{\chi}=\frac{\frac{\alpha_{W} \tilde{m} \tilde{\Psi}}{s+r^{\star}}}{\left(\tilde{L}_{P}\right)^{1 / \sigma_{L}}}$ represents the share of the surplus associated with a labor contract in the marginal benefit of search, $\eta_{\mu, N}<0$ is the elasticity of the markup to entry and $\eta_{N, L}>0$ the elasticity of entry to employment.

\section{Condition for Saddle-Path Stability}

We now derive the saddle-path stability condition and show that the price-elasticity of demand plays a pivotal role in producing potential dynamic instability. Denoting by $\nu$ the eigenvalue, the characteristic equation for the matrix $J(37)$ of the linearized system is given by:

$$
\left(s+r^{\star}-\nu_{i}\right)\left\{\nu_{i}^{2}-r^{\star} \nu_{i}+\frac{D e t J}{s+r^{\star}}\right\}=0 .
$$

\footnotetext{
${ }^{12}$ We show in a Technical Appendix available upon request from the authors that imposing the Hosios condition does not affect our main results. We set $\alpha_{V}=1-\alpha_{W}$ only for clarity purpose.
} 
Saddle-path stability requires $\frac{D e t J}{s+r^{\star}}<0$. Hence, the following inequality must hold:

$$
\frac{\left(1-\alpha_{V}\right) \tilde{\Psi}+\frac{\alpha_{W} \tilde{m} \tilde{\Psi}}{s+r^{\star}}}{-\frac{\eta_{\mu, N} \eta_{N, L}}{\mu}}>\left(\alpha_{V} \tilde{u}+\sigma_{L} \tilde{\chi}\right) .
$$

The trivial special case of exogenous markup implies that $\eta_{\mu, N}=0$ and thereby the inequality (40) above unambiguously holds. If the markup is endogenous, the sign of eq. (40) is not clear-cut and relies in particular upon the intensity of competition. To see it formally, let rewrite $-\eta_{\mu, N} \eta_{N, L} / \tilde{\mu}$ as follows: ${ }^{13}$

$$
-\frac{\eta_{\mu, N} \eta_{N, L}}{\tilde{\mu}}=\frac{1}{e}-\frac{1}{\epsilon}=\left.\frac{1}{\tilde{\mu}}\right|_{\mathrm{N} \text { large }}-\left.\frac{1}{\tilde{\mu}}\right|_{\mathrm{N} \text { limited }} .
$$

As shown by the RHS of eq. (41), the elasticity of the markup to employment is larger when the intensity of competition is initially low, i.e. $\left.\tilde{\mu}\right|_{\mathrm{N}}$ limited ${ }_{\text {is }}$ high. ${ }^{14}$ As a consequence, the saddle-path stability condition is less likely to be fulfilled as the denominator on the LHS of eq. (40) is large. Provided that the intensity of competition is initially high enough, i.e. the number of competitors $N$ is not too small and thereby $\mu$ is not too high, the elasticity of the markup to firm entry is not too large. In this case, inequality (40) is fulfilled and the long-run equilibrium is saddle-path. Beside the intensity of competition in product markets, additional parameters influence the saddle-path stability condition. As shown by the RHS term of inequality (40), the smaller the initial steady-state unemployment rate, $\tilde{u}$, the less responsive labor supply (i.e. the lower $\sigma_{L}$ ), the smaller the worker bargaining power or the larger unemployment benefits (i.e. the lower $\tilde{\chi}$ ), the more likely the condition for saddle-path stability holds.

As long as inequality (40) holds, the linearized dynamic system possesses one negative eigenvalue denoted by $\nu_{1}$ and two positive eigenvalues denoted by $\nu_{2}$ and $\nu_{3}$. Since the number of predetermined variables $(L)$ equals the number of negative eigenvalues and the number of jump variables $(\theta$ and $U$ ) equals the number of positive eigenvalues, the dynamic system exhibits a saddle-point behavior. Eigenvalues satisfy:

$$
\nu_{1}<0<r^{\star}<\nu_{2}<\nu_{3}=s+r^{\star}
$$

and $\nu_{2}=r^{\star}-\nu_{1}>0$.

If inequality (40) does not hold, the determinant of the Jacobian matrix becomes positive, implying that the two characteristic roots $\nu_{1}$ and $\nu_{2}$ have positive real parts. Hence, the dynamic system is locally unstable, and the solutions consistent with an equilibrium converging to the long-run equilibrium is the steady state, i.e. $L(t)=\tilde{L}, \theta(t)=\tilde{\theta}$ and $U(t)=\tilde{U}$.

\footnotetext{
${ }^{13}$ It can be shown that the term $-\eta_{\mu, N} \eta_{N, L} / \tilde{\mu}$ is equal to $1 / \tilde{e}-1 / \epsilon$. By adding and subtracting 1 , and remembering that $\tilde{\mu}=\frac{\tilde{e}}{\tilde{e}-1}$ if the number of competitors is limited or $\tilde{\mu}=\frac{\epsilon}{\epsilon-1}$ if the number of competitors is large, as in the Dixit-Stiglitz specification, we get (41).

${ }^{14}$ More precisely, as $N$ decreases, the gap between $1 / e$ and $1 / \epsilon$ increases so that $-\frac{\eta_{\mu, N} \eta_{N, L}}{\mu}$ becomes large.
} 


\section{Stable Solutions}

The stable paths for employment, labor market tightness, and job seekers are given by :

$$
L(t)-\tilde{L}=A_{1} e^{\nu_{1} t}, \quad \theta(t)-\tilde{\theta}=\omega_{2}^{1} A_{1} e^{\nu_{1} t}, \quad U(t)-\tilde{U}=\omega_{3}^{1} A_{1} e^{\nu_{1} t},
$$

where we normalized $\omega_{1}^{1}$ to unity and elements $\omega_{2}^{1}$ and $\omega_{3}^{1}$ of the eigenvector (associated with the stable eigenvalue $\nu_{1}$ ) are:

$$
\begin{aligned}
& \omega_{2}^{1}=\frac{\left(2 s+r^{\star}\right)+\left(s+r^{\star}-\nu_{i}\right)\left(\frac{s+\nu_{i}}{\tilde{m}}\right)+\frac{\tilde{m} \tilde{\Psi}_{L}}{\tilde{\Psi}_{U}}}{\frac{m^{\prime} \tilde{U}}{\tilde{m}}\left(s+\tilde{m}+r^{\star}-\nu_{i}\right)}, \\
& \omega_{3}^{1}=\left(\frac{s+\nu_{1}}{\tilde{m}}\right)-\frac{m^{\prime} \tilde{U}}{\tilde{m}} \omega_{2}^{1} .
\end{aligned}
$$

The signs of (44) will be determined later.

\subsection{Intertemporal Solvency Condition}

Using the definition of the stock of financial wealth $A(t) \equiv B(t)+\gamma(t) L(t)$, differentiating with respect to time, substituting the accumulation equation of financial wealth and of labor, i.e. eqs. (3) and (2), together with the dynamic equation for the shadow value of an additional worker (22b), using the government budget constraint (see eq. (32)), the accumulation equation for foreign assets is:

$$
\dot{B}(t)=r^{\star} B(t)+\frac{L(t)}{\mu(N(t))}-C(t)-\kappa V(t) .
$$

where $Y(t)=\frac{L(t)}{\mu(N(t))}$ corresponds to output net of fixed costs.

The solution for $B(t)$ consistent with the intertemporal budget constraint for the open economy: ${ }^{15}$

$$
B(t)-\tilde{B}=\Phi(L(t)-\tilde{L}),
$$

where $\Phi \equiv \frac{\Lambda}{\mu_{1}-r^{\star}}$ with $\Lambda=\left(\frac{1-\eta_{\mu, N} \eta_{N, L}}{\tilde{\mu}}\right)-\kappa \tilde{U} \omega_{2}^{1}+\left(v_{L_{P}}-\kappa \tilde{\theta}\right) \omega_{3}^{1}$. We are not able to sign $\Phi$; yet, for all parametrization, numerical results yield $\Phi<0$. The reason is that an increase in employment raises the marginal benefit from hiring (and thereby the shadow price $\gamma$ ), which in turn induces agents to switch investment from foreign assets to labor (i.e. shares on employment agency). As a result, the current account is negatively related to changes in employment. The linear approximation of the open economy's intertemporal budget constraint is:

$$
\tilde{B}-B_{0}=\Phi\left(\tilde{L}-L_{0}\right) .
$$

\footnotetext{
${ }^{15}$ Substituting first the short-run static solutions for the number of firms and consumption into (45), linearizing around the steady-state, substituting the solutions for $L(t), U(t)$ and $\theta(t)$, and invoking the transversality condition, yields eq. (46).
} 
According to (47), the long-run accumulation of employment triggers a long-run fall in foreign bonds holding.

\subsection{Steady-State}

We now describe the steady-state of the economy which comprises six equations. First, the zero-profit condition describes the long-run relationship between the number of firms and both steady-state labor and fixed costs:

$$
\frac{\varphi}{\tilde{L}}=\frac{1}{\epsilon(\tilde{N}-1)+\omega} .
$$

Since the RHS term of eq. (48) decreases as $\tilde{N}$ rises, a fall in fixed costs or a rise in employment raises the steady-state number of firms.

Second, setting $\dot{\theta}=0$ into eq. (34), we obtain the vacancy creation equation:

$$
\frac{\kappa}{f(\tilde{\theta})}=\frac{\left(1-\alpha_{W}\right)}{s+r^{\star}}\left[\frac{1}{\mu(\tilde{N})}-(\tilde{L}+\tilde{U})^{1 / \sigma_{L}}\right]
$$

The LHS term of eq. (49) represents the marginal cost of recruiting. The RHS term represents the marginal benefit of an additional worker which is equal to the share, received by the employment agency, of the rent created by the encounter between a vacancy and a job-seeking worker. Keeping the labor force $\tilde{L}^{P}=\tilde{L}+\tilde{U}$ fixed, a rise in the number of firms raises the marginal benefit of an additional worker which thereby triggers a long-run increase in labor tightness as the employment agency is induced to post more job vacancies.

Third, using the fact that $\tilde{\xi}=\frac{\alpha_{W}}{1-\alpha_{W}} \tilde{\gamma}, \tilde{\gamma}=\frac{\kappa}{\tilde{f}}$, and $\frac{\tilde{m}}{\tilde{f}}=\tilde{\theta}$ to rewrite the reservation wage, the decision of search equation reads as:

$$
(\tilde{L}+\tilde{U})^{1 / \sigma_{L}}=\left[\frac{\alpha_{W}}{1-\alpha_{W}} \kappa \tilde{\theta}+B^{U}\right]
$$

The LHS term of eq. (50) represents the disutility from entering the labor force. The RHS term corresponds to the reservation wage. Since higher labor market tightness increases the probability of hiring and thereby raises the reservation wage, labor force unambiguously increases.

Fourth, setting $\dot{L}=0$ into eq. (2) implies that the flow of unemployed workers who find a job is equalized with the flow of employed workers who lose their job. Using the definition of the labor force, we obtain the standard negative relationship between the unemployment rate and labor market tightness:

$$
\tilde{u}=\frac{s}{s+\tilde{m}} .
$$


Hence, by raising the probability of finding a job, increased labor market tightness lowers the unemployment rate in the long-run.

Fifth, substituting first the short-run static solution for consumption and setting $\dot{B}=0$ into eq. (45), we obtain the zero current account equation:

$$
r^{\star} \tilde{B}+\frac{\tilde{L}}{\mu(\tilde{N})}-C(\bar{\lambda}, \tilde{L}, \tilde{U})-\kappa \tilde{U} \tilde{\theta}=0
$$

where $\frac{\tilde{L}}{\tilde{\mu}}-\tilde{C}-\kappa \tilde{U} \tilde{\theta}$ represents exports.

Finally, the intertemporal solvency condition (47) can be solved for the equilibrium value of the marginal utility of wealth: ${ }^{16}$

$$
\bar{\lambda}=\lambda(\varphi)
$$

Beside the labor force, steady-state consumption is affected by the change in the equilibrium value of the marginal utility of wealth.

\subsection{Graphical Apparatus}

In order to facilitate the discussion of the model, the steady-state is summarized graphically. Focusing mainly on labor market variables, system (48)-(51) can be reduced to two equations. More precisely, eq. (48) solves for a unique number of firms $\tilde{N}=N(\tilde{L}, \varphi)$ while eq. (51), which can be restated as $s \tilde{L}=\tilde{m} \tilde{U}$, enables us to express unemployed workers as a function of employment and labor tightness, i.e. $\tilde{U}=\frac{s \tilde{L}}{\tilde{m}}$. Substituting these functions into eq. (49) and eq. (50) yields:

$$
\begin{aligned}
\tilde{L} & =\frac{\tilde{m}}{\tilde{m}+s}\left[\frac{\alpha_{W}}{1-\alpha_{W}} \kappa \tilde{\theta}+B^{U}\right]^{1 / \sigma_{L}} \\
\frac{\kappa}{f(\tilde{\theta})} & =\frac{\left(1-\alpha_{W}\right)}{s+r^{\star}}\left\{\frac{1}{\mu[N(\tilde{L}, \varphi)]}-\left[\frac{\alpha_{W}}{1-\alpha_{W}} \kappa \tilde{\theta}+B^{U}\right]\right\} .
\end{aligned}
$$

This system jointly determines steady-state employment and labor market tightness and is summarized graphically by Figure 1(a) that depicts the logarithm form of the system in the $(\theta, L)$-space.

The first eq. (54a) represents the decision of search schedule (henceforth $D S$ ) which is upward-sloping in the $(\theta, L)$-space. The reason is that a rise in the labor market tightness

\footnotetext{
${ }^{16} \mathrm{It}$ is worthwhile noticing that the system comprising eqs. (48)-(51) can be solved for the steady-state number of firms, labor market tightness, employment and job seekers. All these variables can be expressed in terms of fixed costs, i.e. $\tilde{L}=L(\varphi), \tilde{\theta}=\theta(\varphi), \tilde{U}=U(\varphi), \tilde{N}=N(\varphi)$. Substituting these equations into (52), we can solve for the stock of foreign assets as a function of the shadow value of wealth and fixed costs: $\tilde{B}=B(\bar{\lambda}, \varphi)$. Finally, plugging $\tilde{B}=B(\bar{\lambda}, \varphi)$ and $\tilde{L}=L(\varphi)$ into eq. (47) yields (53).
} 
raises the probability of finding a job and thereby the reservation wage. Hence, a worker gets a larger share of the surplus associated with a labor contract via higher wage, and thereby is induced to supply more labor.

The second eq. (54b) represents the vacancy creation schedule (henceforth $V C$ ) which is upward-sloping in the $(\theta, L)$-space. The reason is that a rise in the labor market tightness raises the average cost of hiring together with the reservation wage which reduces the surplus from hiring. Hence, to compensate for higher cost and reduced surplus, employment must increase which triggers firm entry and thereby lowers the markup. As long as the condition for saddle-path stability holds, i.e. inequality (40) is satisfied, it can be proven formally that the $V C$-schedule is steeper than the $D S$-schedule. ${ }^{17}$

The intersection, denoted by point $E$, gives the unique solution for steady state labor market tightness $\tilde{\theta}$ and employment $\tilde{L}$. The slope of the stable branch described by eq. (44a) in the $(\theta, L)$-space is ambiguous. If inequality (40) holds, the slope of the stable branch labelled $S S$ is positive and steeper than the locus $\dot{\theta}=0$, as illustrated in Figure 1(a). ${ }^{18}$ Hence, as the economy moves along the $S S$ path to reach the steady-state $E$, labor market and employment co-vary. Let assume that initially, the economy starts with a stock of employment $L_{0}$ smaller than $\tilde{L}$. As employment increases, the markup falls which raises the overall surplus from hiring. As a consequence, the employment agency posts job vacancies which raises labor market tightness.

At this stage, we can provide intuition regarding the saddle-path stability condition. Graphically, if inequality (40) does not hold, the branch $S S$ becomes flatter than the locus $\dot{\theta}=0$ which is less steep than the locus $\dot{L}=0$. Hence, as employment increases, the subsequent rise in the labor market tightness becomes so large that the resulting higher cost of recruiting cannot be longer offset by the drop in the markup. As a consequence, the economy moves away from the steady-state. More precisely, the condition for instability is associated with a low price-elasticity of demand so that the elasticity of the markup with respect to the

\footnotetext{
${ }^{17}$ Formally, we have:$$
0<\left.\frac{\hat{\tilde{L}}}{\hat{\tilde{\theta}}}\right|_{\dot{L}=0}=\left[\alpha_{V} \tilde{u}+\sigma_{L} \tilde{\chi}\right]<\left.\frac{\hat{\tilde{L}}}{\hat{\tilde{\theta}}}\right|_{\dot{\theta}=0}=\frac{\left[\left(1-\alpha_{V}\right) \tilde{\Psi}+\left(\tilde{L}_{P}\right)^{1 / \sigma_{L}} \tilde{\chi}\right]}{-\frac{\eta_{\mu, N \eta_{N, L}}}{\tilde{\mu}}} .
$$

${ }^{18}$ Denoting by a hat the rate of change relative to initial steady-state, the slope of the stable branch in the $(\theta, L)$-space can be written as:

$$
\left.\frac{\hat{L}(t)}{\hat{\theta}(t)}\right|_{S S}=\frac{1}{\omega_{2}^{1}} \frac{\tilde{\theta}}{\tilde{L}}=\frac{\frac{\left(s+\tilde{m}+r^{\star}-\mu_{1}\right)}{\left(s+r^{\star}\right)}\left(1-\alpha_{V}\right) \tilde{\Psi}}{-\frac{\eta_{\mu, N} \eta_{N, L}}{\mu}} .
$$

Since $\frac{\left(s+\tilde{m}+r^{\star}-\mu_{1}\right)}{\left(s+r^{\star}\right)}>\frac{\left(s+\tilde{m}+r^{\star}\right)}{\left(s+r^{\star}\right)}$, the $S S$-schedule is steeper than the $V C$-schedule in the $(\theta, L)$-space.
} 
flow of entry is large. As a consequence, the successive waves of increased labor demand and job vacancies along the transitional path triggers a destabilizing adjustment by raising the marginal cost of hiring above its marginal benefit. ${ }^{19}$ To prevent such destabilizing dynamics, all labor market variables must jump instantaneously to a new steady-state. In contrast to the case of a saddle-path long-run equilibrium, a fall in fixed cost has detrimental effects on labor-market outcomes when the system is unstable: employment and labor market tightness jump immediately to lower steady-state levels. Since the markup is very sensitive to entry, intermediate-good producers find it optimal to lower immediately the firm size by cutting employment. ${ }^{20}$ As profit opportunities decline sharply, the steady-state number of firms is smaller and thereby the markup rises in the long-run. Additionally, the long-run fall in the surplus from hiring results in a smaller labor market tightness as the employment agency is induced to post less job vacancies.

The labor market can alternatively be summarized graphically in the $(u, L)$-space as shown in Figure 1(b). Using eq. (51), we find a negative relationship between the steady-state unemployment rate and labor market tightness. Hence, both the locus $\dot{L}=0$ and $\dot{\theta}=0$ display a negative slope in the $(u, L)$-space. As long as inequality (40) holds, the $V C$-schedule is steeper than the $D S$-schedule in the $(u, L)$-space. Additionally, as illustrated in Figure 1(b), the stable branch labelled $X X$ is downward-sloping but flatter than the $D S$-schedule. Along the stable transitional path, employment and the unemployment rate vary in opposite direction. The reason is that a rise in hours worked raises the employment rate $l \equiv L / L_{P}$ which in turn lowers the unemployment rate $u$.

$<$ Please insert Figure 1 about here $>$

\section{Deregulation Shock: An Analytical Exploration}

In this section, we explore the macroeconomic effects of a deregulation shock, i. e. a fall in fixed costs, with a focus on labor market variables. ${ }^{21}$

\footnotetext{
${ }^{19}$ The flow of entry is so large that employment and labor market tightness would increase indefinitely.

${ }^{20}$ Intermediate-good produces know perfectly that raising employment creates profit opportunities which yield entry along the transitional path. To prevent entry, they produce less and thereby reduce firm size.

${ }^{21}$ Because fixed costs lower firm entry by reducing profit opportunities, such recurring costs act like a cost of entry. As stressed previously, whereas the introduction of a cost of entry would leave unchanged our main results, the dynamics could no longer be analyzed analytically, making use of phase diagrams. Both analytical and numerical results for the firm entry-exit model are available on request from the authors.
} 
Denoting by a hat the rate of change relative to initial steady-state, the long-run effects of a deregulation shock in product markets are ambiguous: ${ }^{22}$

$$
\begin{aligned}
\frac{\hat{\tilde{L}}}{\hat{\varphi}} & =\frac{\frac{\eta_{\mu, N} \eta_{N, L}}{\tilde{\mu}}\left[\alpha_{V} \tilde{u}+\sigma_{L} \tilde{\chi}\right]}{\left[\left(1-\alpha_{V}\right) \tilde{\Psi}+\left(\tilde{L}_{P}\right)^{1 / \sigma_{L}} \tilde{\chi}\right]+\frac{\eta_{\mu, N} \eta_{N, L}}{\tilde{\mu}}\left[\alpha_{V} \tilde{u}+\sigma_{L} \tilde{\chi}\right]} \gtrless 0, \\
\frac{\hat{\tilde{\theta}}}{\hat{\varphi}} & =\frac{\frac{\eta_{\mu, N} \eta_{N, L}}{\tilde{\mu}}}{\left[\left(1-\alpha_{V}\right) \tilde{\Psi}+\left(\tilde{L}_{P}\right)^{1 / \sigma_{L}} \tilde{\chi}\right]+\frac{\eta_{\mu, N} \eta_{N, L}}{\tilde{\mu}}\left[\alpha_{V} \tilde{u}+\sigma_{L} \tilde{\chi}\right]} \gtrless 0,
\end{aligned}
$$

where $\tilde{\Psi}>0, \tilde{\chi}>0, \eta_{\mu, N}<0$ and $\eta_{N, L}>0$.

In a polar case where the markup is fixed, then $\eta_{\mu, N}=0$ and both steady-state employment and labor market tightness remain unaffected by the drop in $\varphi$.

When the markup is negatively correlated with the number of competitors, depending on whether the saddle-path stability condition holds or not, a fall in fixed costs raises or lowers employment. If inequality (40) is fulfilled, i.e. the intensity of competition is initially not too low, as illustrated in Figure 2(a), a drop in fixed costs shifts to the right the $V C$-schedule which raises both $\tilde{\theta}$ and $\tilde{L}$.

A drop in $\varphi$ has more beneficial effects in labor market outcomes as the elasticity of labor force $\sigma_{L}$ is higher. Graphically, raising $\sigma_{L}$ rotates to the left the $D S$-schedule. Hence, a deregulation shock raises further $\tilde{L}$ and $\tilde{\theta}$ as the $V C$-schedule moves along a steeper locus $\dot{L}=0$. The reason is that for a given increase in the reservation wage triggered by the rise in $\tilde{\theta}$, households are more willing to join the labor force. Hence, employment increases further.

Two additional labor market parameters play a pivotal role: the worker bargaining power $\alpha_{W}$ and unemployment benefits $B^{U}$. A higher $\alpha_{W}$ and/or a smaller $B^{U}$ rotates to the left the $D S$-schedule by raising the share of the surplus associated with a labor contract in the marginal benefit of search $\tilde{\chi}$. Hence agents are more willing to join the labor force which in turn raises further employment.

Initial labor market conditions and product market competition also influence the size of the long-run effects of a deregulation shock. Inspection of eq. (55a) shows that countries having initially higher unemployment rate $\tilde{u}$ and poorly competitive product markets as captured by a larger markup $\tilde{\mu}$ will experience a larger increase in employment. Graphically, raising $\tilde{u}$ rotates to the left the $D S$-schedule. The reason is that a higher unemployment rate must be associated with a smaller $\tilde{\theta}$ which implies a stronger reaction of employment to a given change in the reservation wage. Poor competitive conditions in the product markets lead to a smaller number of competitors and thereby a larger elasticity of the markup to firm entry

\footnotetext{
${ }^{22}$ The signs of eqs. (55a)-(55b) are not clear-cut since the denominator can be negative or positive, while the numerator is unambiguously negative.
} 
(see eq. (41)). Hence, labor market tightness increases more following a deregulation shock, and employment as well. Graphically, raising $\tilde{\mu}$ rotates to the right the $V C$-schedule which becomes less steep.

We turn now to the transitional dynamics which are illustrated in Figures 2(a) and 2(b). By reducing average costs, a fall in fixed costs $\varphi$ fosters firm entry and thereby raises the number of firms. As intermediate good producers perceive a more elastic demand, as reflected by a decline in the markup, they are induced to produce more by renting additional labor services. Higher labor demand raises the marginal cost of labor services W. Because the surplus from hiring increases, the employment agency posts additional job vacancies which in turn raises the labor market tightness on impact. The economy moves instantaneously from $E_{0}$ to point $E^{\prime}$, as displayed in Figure 2(a). The consecutive increase in the reservation wage provides an incentive to enter the labor force. Hence, the number of job seekers increases. Since labor is a state variable and thereby is initially predetermined, the unemployment rate increases abruptly from $\tilde{u}_{0}$ to $u(0)$ as the economy moves from $F_{0}$ to $F^{\prime}$ (see Figure 2(b)). Over time, employment builds up which reduces further average costs and triggers additional firm entry. As labor demand increases, the surplus from hiring rises further. Hence, the employment agency posts additional job vacancies. As a consequence, as stressed previously, employment and labor market co-move along the transitional path $S S$. In the same time, the number of job seekers declines after its initial rise because increased employment raises the marginal cost of search, i.e. the disutility from entering the labor force. Yet, the rise in employment more than offsets the decline of job seekers so that the labor force increases gradually. The subsequent growth in the employment rate drives down $u$, as illustrated in Figure 2(b). When the economy reaches the final steady-state, employment and labor tightness are higher while the unemployment rate is smaller.

One major feature of the propagation mechanism of a deregulation shock is that the combined effect of the elastic labor supply and endogenous markups produces a multiplicative effect on labor market variables. As the markup depends on aggregate employment, the increase in labor force participation, triggered by the rise in the labor market tightness (which raises the reservation wage), reduces the markup which in turn raises further the labor market tightness and so on. The larger the elasticity of labor supply, the greater the successive waves of declining magnitude.

\footnotetext{
$<$ Please insert Figure 2 about here $>$
} 


\section{Deregulation Shock: A Quantitative Exploration}

While the model can be solved analytically, we propose some numerical simulations to illustrate key theoretical results.

\subsection{Baseline Parametrization}

We start by discussing our calibration of the model's parameters. The world interest rate $r^{\star}$ which is equal to the subjective time discount rate $\rho$ is set to $1 \%$. One period of time corresponds to a quarter. Below, we analyze two different calibrations of the model, one aimed at capturing the European labor markets "rigidities", the other aimed at capturing the U.S. labor markets. For these two calibrations, we present the implications of a deregulation shock.

Our reference period for the calibration corresponds to the pre-deregulation episode, i.e. 1995-1998. While some European countries started earlier like the U.S. or the U.K., i.e. at the end of the seventies or the beginning of the eighties, most of the European countries did not improve competitive conditions in the product market before the signature of the Maastricht Treaty. Further, the period over which the deregulation in product markets fastens coincides with the entry in the euro area. More precisely, the value added weighted sum of fifteen EU members' product market regulations indices show that the largest decrease in the indicator was in $1999 .{ }^{23}$ Hence, we choose $1995-1998$ as the pre-deregulation period to calibrate our model. Data are summarized in Table 4.

We start with the values of the labor market parameters which are chosen so as to match a typical European economy. Some of the values of the labor market parameters can be taken directly from data, but others need to be endogenously calibrated to fit a set of labor market features. As summarized in Table 4, unemployment rate and the job finding rate average $10 \%$ and 0.2 respectively for Europe (15). Hence, the matching efficiency parameter $M_{0}$ has been set to 0.35 and the job destruction rate $s$ to 0.023 to target an unemployment rate $u$ of $10 \%$ and a quarterly job finding rate $m$ of 0.2 , in line with the data shown in Table 4. According to estimates by Petrongolo and Pissarides [2001], the elasticity of the matching function with respect to unemployment falls in the range of 0.3 to 0.7 . We set $\alpha_{V}=0.5$, as it is common in the literature. Because we impose the Hosios [1990] condition, we set the worker bargaining power $\alpha_{W}$ to $0.5 .^{24}$ In the numerical analysis, we assume that

\footnotetext{
${ }^{23}$ We use the aggregate indicator of regulation in energy, transport and communications. Source: Conway, De Rosa, Nicoletti, and Steiner [2006]. Data and calculations are available from the authors.

${ }^{24}$ The empirical literature usually finds small values for the worker bargaining power. Using a panel of French manufacturing firms, Crépon, Desplat Mairesse [1999] estimate that workers capture $25 \%$ of the rent
} 
unemployment benefits are a fixed proportion of the wage rate, i.e. $B^{U}=\tau^{U} w$, with $\tau^{U}$ the replacement rate. The unemployment benefit replacement rate has been set to $65 \%$, in line with our estimates shown in Table 4 . The next step is to choose a value for $\kappa$ which reflects the recruiting cost. To target a labor market tightness $\theta$ of 0.5 , a reference value for most of the matching literature for the U.S., we set the share of recruiting costs in GDP to $2 \%$ by choosing $\kappa=0.575$ when calibrating for the U.S. economy. Then we keep this value of $\kappa$ for Europe. In this case, we obtain $\theta=0.35$ for the baseline scenario.

To capture the U.S. labor market, we set the matching efficiency parameter $M_{0}$ to 1.25 and the job destruction rate $s$ to 0.05 to target an unemployment rate $u$ of $5 \%$ and a quarterly job finding rate $m$ of 0.9 , in line with the data shown in Table 4 . Furthermore, the unemployment benefit replacement rate has been set to $55 \%$. We keep other parameters unchanged.

Next, we turn to the parameters for which we conduct some sensitivity analysis: the Frisch elasticity of labor supply at the extensive margin $\sigma_{L}$, and the degree of competition in product markets as captured by the markup $\mu$. Empirical studies based on micro data generally report much larger values for the Frisch elasticity of labor supply on the extensive margin than on the intensive margin. More precisely, while the former falls in the range of 0.6 to 0.8 , the latter falls in the range of 0.1 to 0.5 . We choose $\sigma_{L}$ to be 0.5 in our baseline setting. ${ }^{25}$ In the light of data summarized in Table 4, the markup in EU-15 countries over the period 1995-1998 averages 1.4. We set the elasticity of substitution among sectoral goods $\omega$ to 1 and the elasticity of substitution among intermediate goods $\epsilon$ to 3.8 to target a markup of $1.4 .^{26}$

Numerical results are reported in Table 2. Since data show considerable heterogeneity across European Union members, we conduct a sensitivity analysis with respect to pivotal parameters capturing the regulation of goods and labor markets. We consider six alternative while Cahuc, Gianella, Goux and Mairesse [1998] find the workers have an average bargaining power of about 0.2. More recently, estimates by Cahuc, Postel-Vinay and Robin [2006] show that the worker bargaining power falls in the range between 0-40\%, depending on the particular industry considered and workers' skills. We set $\alpha_{W}$ to 0.5 but conduct a sensitivity analysis with respect to this parameter, setting alternatively $\alpha_{W}$ to 0.2 and 0.8 .

${ }^{25}$ Using the Panel Study of Income Dynamics, Fiorito and Zanella [2008] find that aggregate time-series results deliver a Frisch elasticity of about 0.8, the contribution of employment (extensive margin) accounting for about 4/5 of the aggregate elasticity. Using Japanese data, Kuroda and Yamamoto [2007] report a Frisch elasticity on the extensive margin which falls in the range of 0.6 to 0.8 for both sexes.

${ }^{26}$ Due to the lack of empirical evidence regarding the elasticity of substitution among sectoral goods $\omega$, we set this parameter to 1 and choose a value for $\epsilon$ to target a markup of 1.4. In our baseline setting, the choice of parameter values implies a share of fixed cost in GDP of $28 \%$. This value is close to the ratio chosen by Jaimovich and Floetotto [2008]. Furthermore, consumption expenditure and government spending, as a share of initial GDP are $57 \%$ and $20 \%$, respectively. 
scenarios: benchmark parametrization (i. e. , $\sigma_{L}=0.5, \alpha_{W}=0.5, \epsilon=3.8$ ), a larger worker bargaining power (i. e., $\alpha_{W}=0.8$ ), a smaller worker bargaining power (i. e., $\alpha_{W}=0.2$ ), poorly competitive product markets (i. e., $\epsilon=2.5$ ), a weakly responsive labor force (i. e. , $\sigma_{L}=0.2$ ), a highly responsive labor force (i. e. , $\left.\sigma_{L}=1\right) .{ }^{27}$ The seventh column displays the results for the calibration aimed at capturing the United States.

\subsection{Calibrating the Deregulation Shock}

We are interested in evaluating the size of unemployment effects triggered by a decline in product market regulation, captured by a fall in fixed costs in our theoretical framework. To calibrate the size of the deregulation shock, we adopt the following strategy. We estimate by how much the markup falls following a decrease in the product market regulation. To do so, we choose a particular deregulation phase in the EU-15 countries, corresponding to the period ranging from 1999 to 2005. During this period, EU-15 countries have experienced their fastest deregulation episode, measured by the OECD non-manufacturing regulatory index. More precisely, the weighted sum of fifteen EU members' PMR indices has decreased by 1 unit, i.e. from 2.8 to 1.8 , which corresponds to the fastest decline in this index during the last thirty years. ${ }^{28}$ Hence, when we simulate the model, we consider a fall in fixed costs which lowers the markup by the same amount equivalent to the above mentioned drop in the PMR index. In adopting this strategy, we believe that we can get some sense of the magnitude of the effects that the fall in fixed costs we consider in numerical experiments might generate.

Following a vast empirical literature (see e.g., Tybout [2003], Griffith et al. [2007], Boulhol [2010]), we use price-cost margins as a proxy of market power. We compute the price-cost margin denoted by $\mu$ as value added over the sum of labor cost plus capital cost, all variables measured in current prices: ${ }^{29}$

$$
\mu_{i j t}=\frac{\text { Value added }_{i j t}}{{\text { Labor } \text { Costs }_{i j t}+\text { Capital Costs }_{i j t}}},
$$

where $i$ indexes countries, $j$ the sector and $t$ years.

Our strategy is to evaluate how much the markup has decreased in Europe as a result of the deregulation movement in the product markets. To do so, we regress the markup on

\footnotetext{
${ }^{27}$ Setting $\epsilon$ to 2.5 yields a markup of 1.7 .

${ }^{28}$ Calculations are available from the authors.

${ }^{29} \mathrm{An}$ important advantage of price-cost margin as a measure of market power is that it can vary both across industries and over time. An alternative approach would be to estimate the markups by applying the methodology developed by Roeger [1995]. One problem with this approach is that the time dimension would be sacrificed. The drawback of estimating markups by using price-cost margins is that this measured of market power is biased downwards in the presence of increasing returns to scale, see Roeger [1995].
} 
indicators of product market regulation. To capture the intensity of regulation over time, we use the time-series regulatory indicators in product market provided by OECD. These regulatory indicators measure on a scale from 0 to 6 restrictions on competition, in particular barriers of entry and public ownership, which are available for two 1-digit ISIC-rev.3 industries, namely Electricity, gas, and water supply and Transport, storage and communications. Our sample includes 16 OECD countries and covers the period $1985-2003 .{ }^{30}$ For these countries, the price-cost margins average 1.1 and 1.3 in Transport, communication and Electricity, gas, and water supply, respectively. We run regressions from 1985 until 2003, except specifications (3) and (4) where data for bargaining coverage end in 2000.

Labor market institutions also influence the price-cost margin by affecting the worker bargaining power and the reservation wage. ${ }^{31}$ Following Griffith et al. [2007], we explore the following relationship empirically:

$$
\mu_{i j t}=f_{i}+g_{j}+t_{t}+P M R_{i j t} \beta_{1}^{\prime}+L M R_{i t} \beta_{2}^{\prime}+X_{i j t} \beta_{3}^{\prime}+\epsilon_{i j t},
$$

where $P M R$ represents a set of of time, country, and sector varying indicators of product market regulations, $L M R$ contains a set of time and country varying indicators of labor market regulations and institutions, and $X$ represents a set of controls, including a measure of the deviation of sectoral output from trend and the change in the sectoral inflation rate. Indicators of labor market regulations and institutions include: tax wedge, replacement rate of unemployment benefits, employment protection legislation, union coverage, coordination. Country fixed effects are captured by country dummies, $f_{i}$, sectoral fixed effects by sector dummies, $g_{j}$, and common macroeconomic shocks by year dummies, $t_{t}$.

The estimation method which has been used is based on standard panel data techniques, using Driscoll and Kraay [1998] standard errors for the estimated coefficients. ${ }^{32}$ Results are reported in Table 1. We restrict our comments of the results related to variables in our model. In column (1), we regress the price-cost margin on the indicator of product market regulation without controls for labor market regulations. Our panel data estimations suggest that a 1 unit decrease in PMR lowers the markup by 0.028 percentage points. In column (2), we add

\footnotetext{
${ }^{30}$ These countries are: AUS, AUT, BEL, CAN, DEU, DNK, FIN, FRA, GBR, ITA, NLD, NOR, NZL, SPA, SWE, USA.

${ }^{31}$ Boulhol [2010] analyzes the determinants of price-cost margins at sector manufacturing level for OECD countries between 1970 and 2003. Constructing a static theoretical framework with monopolistic competition and imperfect labor markets, Boulhol establishes that the higher the worker bargaining power and the stronger the intensity of competition, the lower the price-cost margin. Additionally, an increase in the tax wedge or in the replacement rate raises the reservation wage which should result in a smaller markup.

${ }^{32}$ According to Driscoll and Kraay [1998], these standard errors are robust to very general forms of crosssectional as well as temporal dependence, which may very likely plague our macro level variables.
} 
controls for the labor markets which amplify the fall in the markup up to 0.033 percentage points. Employment protection legislation has the expected sign and is significant. In column (3), we add bargaining coverage and the coordination index as labor market controls. Their coefficients have the expected sign but only the bargaining coverage has a significant impact (at $1 \%$ ) on $\mu$. In column (4), we split the regulatory index in two indicators, namely public ownership and cost of entry. Interestingly, both measures raise significantly the markup, public ownership exerting the strongest impact. ${ }^{33}$

Following these empirical results, the price-cost margin response to a product market regulation falls in the range of 2.8 to 3.3 percentage points over the period 1985-2003. In the sequel, when simulating the model, we will adopt a fall in fixed costs which reduces the markup by 3 percentage points.

$<$ Please insert Table 1 about here $>$

\subsection{Long-Run and Dynamic Effects of Deregulation in Product Markets}

We now discuss the quantitative effects of a deregulation shock. The rise in the intensity of competition following the decline in fixed costs lowers the markup from 1.4 to about 1.37 in the baseline scenario.

\section{Long-Run Effects}

In panel A of Table 2 we report numerical results for long-run effects of a deregulation shock. The subsequent increase in employment falls in the range between $0.45 \%$ of initial steady-state labor force if $\sigma_{L}=0.2$ and $2.75 \%$ if $\sigma_{L}=1$. As stressed previously, the interaction between endogenous labor force participation and endogenous markups produces a multiplicative effect on employment. The more responsive the labor supply at the extensive margin, the larger the successive increases in $\theta$ of declining magnitude, the greater the long-

\footnotetext{
${ }^{33}$ In all cases, the replacement rate is significant but has an unexpected sign. A possible explanation to this fact could be that higher unemployment benefits lower the labor market tightness which in turn reduces the reservation wage and thereby raises the markup. As long as all controls for labor market institutions are included, the coefficient associated to tax wedge has the predicted sign but is never significant. In all specifications, a change in the inflation rate has a negative effect on the price-cost margin and is statistically significant in specifications (3) and (4), i.e. when all labor market controls are included in the regression. According to the predictions of the model developed by Boulhol [2010], the negative impact of the change in the inflation rate on price-cost margins could be explained by price-stickiness. Finally, according to estimates by Nekarda and Ramey [2010], we expect procyclical markups. Yet, perhaps due to the specificity of the sectors, our regressions fail to detect a systematic and statistically positive impact on price-cost margins.
} 
run rise in labor. Furthermore, the combined effect of the decline in the markup reflecting a rise in the labor cost paid by intermediate-good producers (due to additional labor demand) and the increase in the reservation wage raises significantly the Nash bargaining wage $w$. As shown in the seventh line, the wage growth increases from $1.96 \%$ to $2.84 \%$ as $\sigma_{L}$ is raised from 0.2 to 1 . The fifth line of Panel A indicates that by and large, the number of job seekers $U$ remains almost unchanged because the inflow in unemployment is offset by the outflow from unemployment.

The decline in the unemployment rate (i.e., $\tilde{u} \equiv 1-\tilde{l}$ ) is moderated, namely between 0.06 and 0.22 percentage point. This finding is in line with the result reached by Ebell and Haefke [2009]. Yet, in our model, all or the major part of the fall in $u$ can be attributed to the increased labor force. Numerical results show that the workers' bargaining power play a pivotal role. Raising $\alpha_{W}$ from 0.2 to 0.8 amplifies the decline in the unemployment rate from 0.06 to 0.22 percentage points of the labor force. The reason is that as workers obtain a larger share of the surplus, they are more willing to supply labor. By reducing further the markup, this effect compensates the fact that the employment agency receives a smaller share of the surplus from hiring. Moreover, we find that the unemployment rate is weakly sensitive to the elasticity of labor supply at the extensive margin. The reason is that raising $\sigma_{L}$ amplifies substantially the inflow in unemployment, as shown in the fifth line of Table 2.

The numbers shown in the first and the seventh column of Table 2 compares the change of labor market variables for a calibration capturing Europe and the U.S., respectively. By and large, beneficial effects in labor market outcomes are larger in Europe than in the United States. In particular, a deregulation shock results in a smaller decline in the U.S. unemployment rate than that in Europe, i.e. 0.05 rather than 0.1 percentage point. On the one hand, a lower unemployment benefit replacement rate provides a greater incentive to supply more labor following an increase in the reservation wage, i.e. $\tilde{\chi}$ is larger in the U.S. than in Europe in our baseline calibration. This effect amplifies the decline in the unemployment rate after a deregulation shock. On the other hand, a lower initial steady-state unemployment rate $\tilde{u}$ implies a smaller elasticity of the employment rate to labor market tightness (keeping unchanged reservation wage). According to numerical results, the latter effect predominates which results in a larger impact on employment. As a result, labor market tightness increases more in Europe which amplifies the rise in the Nash bargaining wage $(2.25 \%$ rather than $2.07 \%$ ) by raising further the reservation wage.

Numerical results also show that consumption increases substantially, ranging from $1.7 \%$ of initial GDP to almost 4\% (see the last line of panel A of Table 2). The rise in consumption 
comes from higher labor income and higher dividends paid by the employment agency to households.

$<$ Please insert Table 2 about here $>$

$<$ Please insert Figure 3 about here $>$

\section{Dynamic Effects}

In panel $\mathrm{B}$ of Table 2 we report numerical results for impact effects. The computed transitional paths of key variables under the baseline scenario (solid line) are displayed in Figure 3 and are compared to alternative scenarios. The dashed line shows results for smaller worker bargaining power, the dashed-dotted line for an economy with initially low intensity of competition in product markets, and the thin solid line for a higher elasticity of labor supply at the extensive margin. The responses of labor market variables are expressed in percent of initial steady-state labor force, with the exception of the Nash bargaining wage and the firm size which are expressed in percentage deviation from its initial steady state. Flow of entry corresponds to the deviation of the current number of firms from its initial steady-state value. Horizontal axes measure quarters.

The cut in overhead costs creates profit opportunities which induces new firms to enter the market. Because the number of firms is a jump variable, the markup falls abruptly. The consecutive increase in labor demand provides an incentive to post job vacancies, and more so in economies with a small worker bargaining power or a highly responsive labor force participation. As summarized in Table 2, job vacancies rises by $1.84 \%$ and $1.15 \%$ of initial labor force if $\alpha_{W}=0.2$ or $\sigma_{L}=1$, respectively, while $V / L_{P}$ increases by $0.50 \%$ in the baseline scenario. In the former case (i.e. $\alpha_{W}=0.2$ ), the employment agency receives a larger share of the surplus which provides a stronger incentive to post more job vacancies. In the latter case (i.e. $\sigma_{L}=1$ ), because labor force participation is more elastic, employment increases more which lowers further the markup and thereby raises labor demand by a larger amount.

As shown in the fourth line of Table 2 , because the higher reservation wage provides an incentive to participate in the labor market, the unemployment rate increases sharply; the rise of $u$ ranges from 0.36 to 2.50 percentage points as $\sigma_{L}$ is raised from 0.2 to 1 . Increasing $\sigma_{L}$ amplifies the number of job seekers while labor remains unchanged on impact as $L$ is initially predetermined. Furthermore, the wage rate rises substantially on impact, and more so in 
economies with higher workers' bargaining power, initially poorly competitive product markets, or strongly responsive labor supply. If product markets are initially strongly regulated, $\mu$ falls further as the elasticity of the markup to entry is larger. Hence, labor demand increases more which raises further the Nash bargaining wage. It is worth noting that a deregulation shock lowers significantly the firm size on impact as employment remains unchanged while entry of new firms lowers output per firm.

Over time, employment builds up which creates profit opportunities, as depicted in Figure 3(a). Hence, as illustrated in Figure 3(g), the number of firms increases which results in a decline in the markup. As a consequence, the employment agency posts job vacancies so that the labor market tightness increases monotonically over time, as displayed in Figure 3(b). The consecutive rise in the reservation wage induces agents to supply more labor. The inflow in unemployment pursues, though it slows down over time (see Figure 3(d)). As illustrated in Figure 3(e), after its initial upward jump, the unemployment rate declines over time as employment keeps on increasing along the transitional path. Importantly, the unemployment rate exceeds its original value over almost twelve quarters (i.e. three years). Figure 3(f) shows that the combined effect of an increasing reservation wage and a declining markup, the latter resulting in greater labor demand, pushes up the Nash bargaining wage. Production expands which raises firm size along the transitional path, as shown in Figure 3(h).

\subsection{Deregulation in Product Markets and the Labor Share}

Blanchard and Giavazzi [2003] find that a deregulation shock has a positive impact on the share of labor income in output. We confirm this result numerically, though the long-run response of the labor share remains fairly muted.

To write out the shares of profit and labor income in GDP, we have to remember that overall profit plus labor income is equal to output less total fixed costs and the cost of recruiting (see eq. (31)):

$$
N \pi^{P}+\Pi^{H}+w L=Y-N \varphi-\kappa V \equiv Q .
$$

Denoting by $\Pi \equiv N \pi^{P}+\Pi^{H}$ overall profits, the share of labor income is given by:

$$
\frac{w L}{Q}=1-\frac{\Pi}{Q}
$$

The labor share may fall or rise depending on whether the increase in labor income $w L$ is larger or smaller than that of $Q$. Numerical results provided in the eighth line of panel A of Table 2 show that the steady-state labor share never decreases in all scenarios, but rather remains fairly stable. 
By contrast, in the short-run, the labor share $w L / Q$ rises substantially, and more so in countries where the workers' bargaining power is smaller, product markets are initially highly regulated, labor supply at the extensive margin is higher. As $\alpha_{W}$ is reduced, net output $Q$ increases much less as the cost of hiring absorbs more resources because $V$ rises further. If competition in product markets is initially low, a deregulation shock shifts the labor demand by a larger amount which results in higher wages. Raising the elasticity of labor supply pushes up further the reservation wage as $\theta$ increases more.

The figures shown in the first and the seventh column of Table 2 compare the change of the labor share for a calibration capturing European and the U.S. labor markets, respectively. Whereas in the former case, as stressed above, the unemployment rate declines more and the product wage rises further, the labor share increases less than in the United States. ${ }^{34}$

\section{Conclusion}

High rates of unemployment remain a key policy concern across many European countries. While labor market institutions have received a lot of attention as the main determinant of unemployment, recent empirical evidence suggest that the degree of regulation in the product markets is an important cause of unemployment. In this paper, we illuminate the dynamic link between product market regulation and unemployment by introducing search unemployment and endogenous markups. In contrast to the previous literature, (i) we derive analytically the condition for saddle-path stability, (ii) fully characterize the transitional paths, and (iii) determine the role of labor market parameters in driving the magnitude of the effects of a deregulation shock, (iv) calibrate the deregulation shock by estimating the relationship between the markup and the product market regulation index provided by OECD.

One major contribution of the paper is to show that a deregulation shock raises labor and lowers the unemployment rate as long as the condition for saddle-path stability is fulfilled. When product markets are initially relatively uncompetitive, instability could emerge and result in detrimental effects on labor market outcomes. If the condition for saddle-path stability holds, employment increases gradually while the unemployment rate rises substantially on impact. Along the transitional path, the combined effect of labor supply and endogenous markups triggers a multiplicative employment effect which amplifies the beneficial effects on labor market outcomes.

Numerical simulations stress three major points. First, both labor and product market

\footnotetext{
${ }^{34}$ The reason is that in the latter case, the employment agency posts more job vacancies and the markup falls less which result in a smaller increase in net output $Q$.
} 
parameters play a pivotal role in driving short-term and long-term effects of a deregulation episode. Countries with higher worker bargaining power and stringent anti-competitive product market regulation would experience larger benefits from improving competitive conditions in goods market. Yet, numerical experiments show that the unemployment rate rises substantially in the short-run and remains higher than its original level over about two years, before decreasing below its original level. Second, due to endogenous labor force participation, the number of job seekers remains almost unchanged because the inflow in unemployment is offset by the outflow from unemployment. The increase in the labor force triggered by higher employment drives down the steady-state unemployment rate, falling in the range between 0.06 and 0.22 percentage point. Third, numerical results show that the increase in the labor share is substantial in the short-run but remains insignificant in the long-run. 


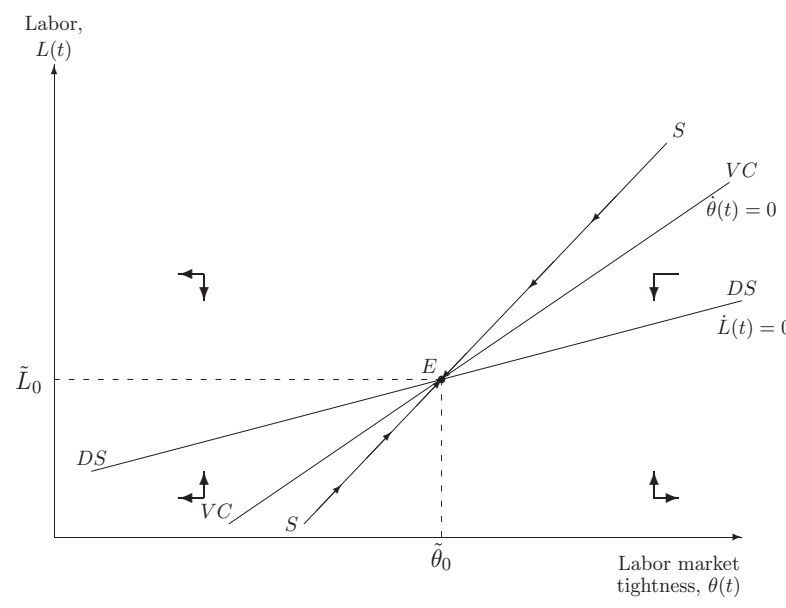

(a) $(\theta, L)$-space

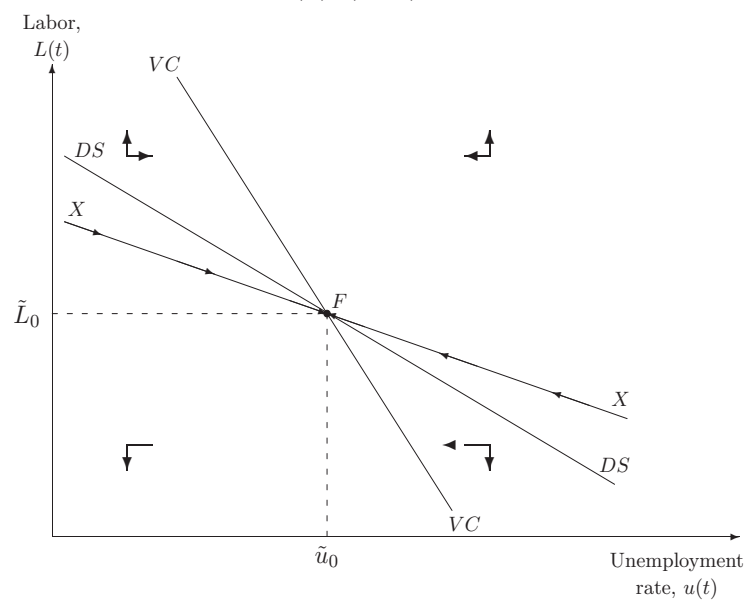

(b) $(u, L)$-space

Figure 1: Phase Diagrams 


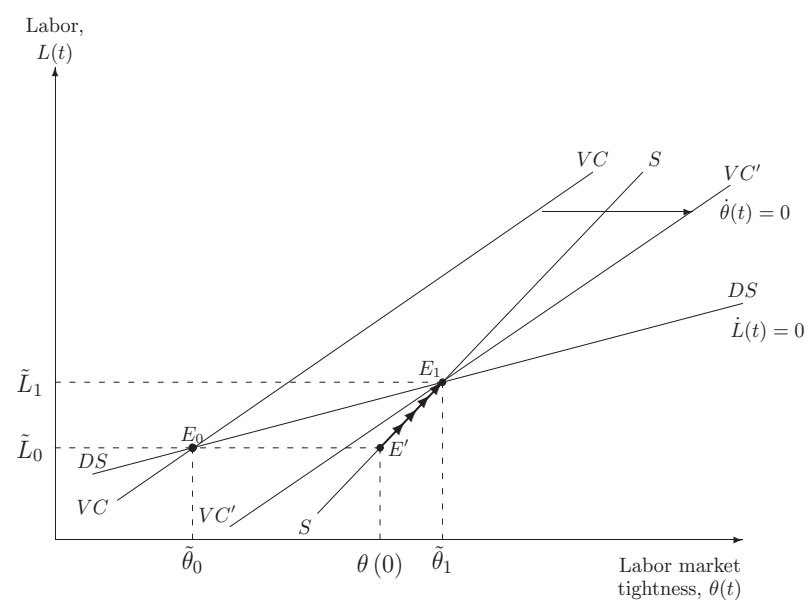

(a) $(\theta, L)$-space

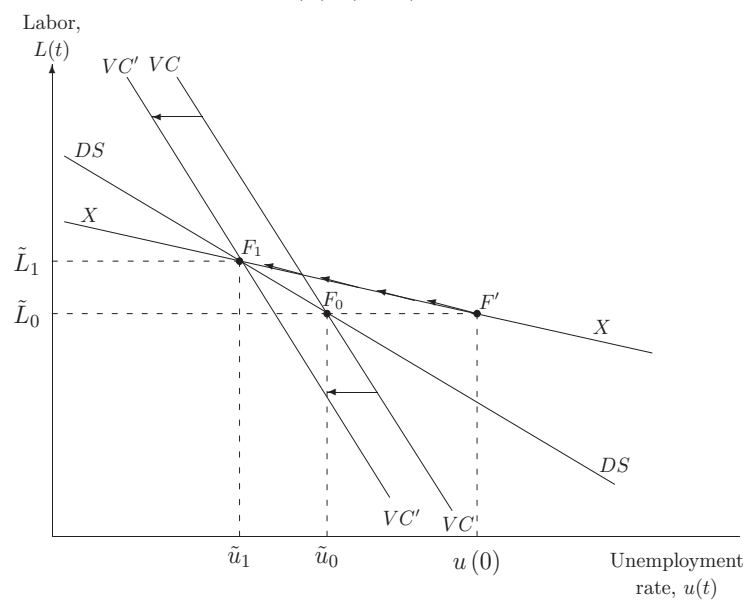

(b) $(u, L)$-space

Figure 2: Effects of a Deregulation Shock and the Stable Adjustment 
Table 1: The Impact of Product Market Regulation on Price-cost Margin

\begin{tabular}{|c|c|c|c|c|}
\hline \multirow{3}{*}{$\begin{array}{l}\text { Dependent variable } \\
\text { Specification } \\
\text { Period }\end{array}$} & \multicolumn{4}{|c|}{ Price-cost Margin } \\
\hline & (1) & $(2)$ & $(3)$ & $(4)$ \\
\hline & $85-03$ & $85-03$ & $85-00$ & $85-00$ \\
\hline Product market regulation & $\begin{array}{c}0.02882^{* * *} \\
(0.008)\end{array}$ & $\begin{array}{c}0.03321^{* * *} \\
(0.008)\end{array}$ & $\begin{array}{c}0.05175^{* * *} \\
(0.007)\end{array}$ & \\
\hline Public ownership & & & & $\begin{array}{c}0.04577^{* * *} \\
(0.007)\end{array}$ \\
\hline Cost of entry & & & & $\begin{array}{c}-0.00190 \\
(0.011)\end{array}$ \\
\hline$\Delta$ Sectoral inflation & $\begin{array}{c}-0.00004 \\
(0.000)\end{array}$ & $\begin{array}{c}-0.00005 \\
(0.000)\end{array}$ & $\begin{array}{c}-0.00365^{* * *} \\
(0.001)\end{array}$ & $\begin{array}{c}-0.00319^{* * *} \\
(0.001)\end{array}$ \\
\hline Sectoral output gap & $\begin{array}{l}0.16497 \\
(0.137)\end{array}$ & $\begin{array}{c}0.19178 \\
(0.139)\end{array}$ & $\begin{array}{c}-0.08930 \\
(0.121)\end{array}$ & $\begin{array}{c}0.01233 \\
(0.169)\end{array}$ \\
\hline Tax wedge & & $\begin{array}{c}0.14284 \\
(0.235)\end{array}$ & $\begin{array}{c}-0.00810 \\
(0.162)\end{array}$ & $\begin{array}{c}-0.11845 \\
(0.159)\end{array}$ \\
\hline Employ. protec. legislation & & $\begin{array}{c}-0.03294^{* * *} \\
(0.012)\end{array}$ & $\begin{array}{c}-0.05639^{* *} \\
(0.025)\end{array}$ & $\begin{array}{c}-0.05404^{*} \\
(0.027)\end{array}$ \\
\hline Replacement rate & & $\begin{array}{c}0.00183^{* *} \\
(0.001)\end{array}$ & $\begin{array}{c}0.00419 * \\
(0.002)\end{array}$ & $\begin{array}{c}0.00607^{* *} \\
(0.003)\end{array}$ \\
\hline Bargaining coverage & & & $\begin{array}{c}-0.00319^{* * *} \\
(0.001)\end{array}$ & $\begin{array}{c}-0.00426^{* * *} \\
(0.001)\end{array}$ \\
\hline Coordination index & & & $\begin{array}{c}-0.02199 \\
(0.021) \\
\end{array}$ & $\begin{array}{c}-0.01967 \\
(0.025) \\
\end{array}$ \\
\hline Observations & 586 & 586 & 114 & 114 \\
\hline Number of countries & 16 & 16 & 16 & 16 \\
\hline Number of sectors & 2 & 2 & 2 & 2 \\
\hline
\end{tabular}

Notes: Fixed effects (sector-country) regressions, using Driscoll-Kraay standard errors in parentheses; $\star$ significant at $10 \%$; $\star \star$ significant at $5 \%$; $\star \star \star$ significant at $1 \%$. 


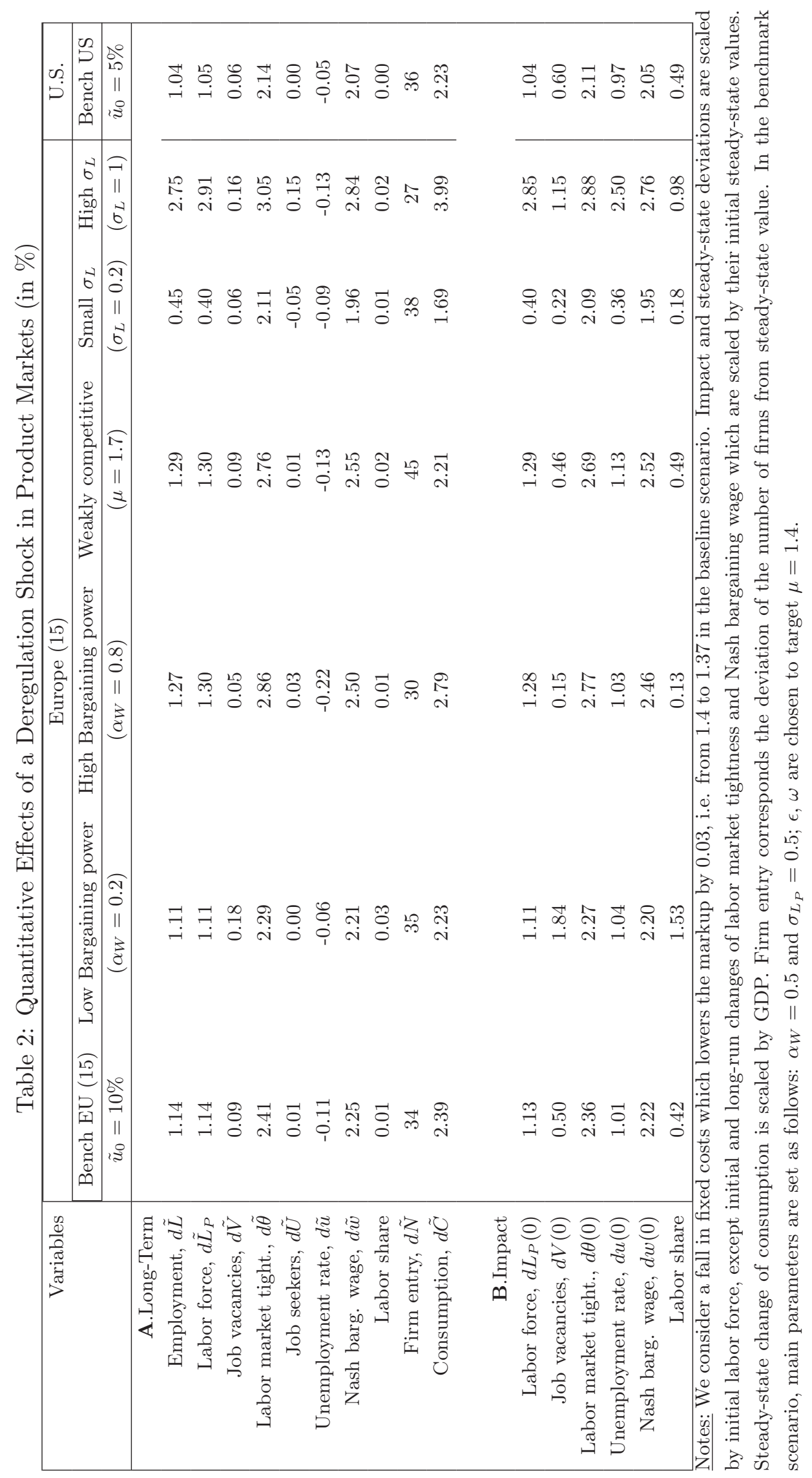


(a) Employment

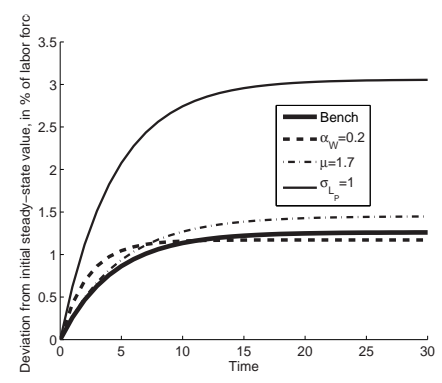

(c) Job vacancies

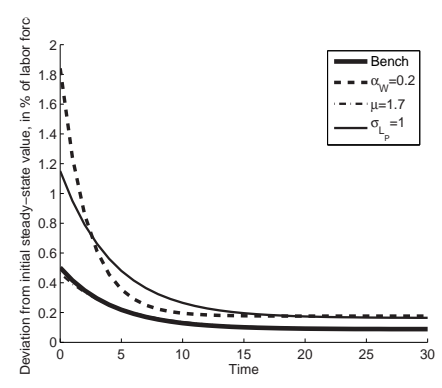

(e) Unemployment rate

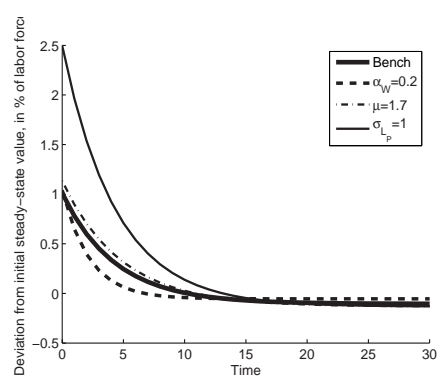

(g) Firm entry

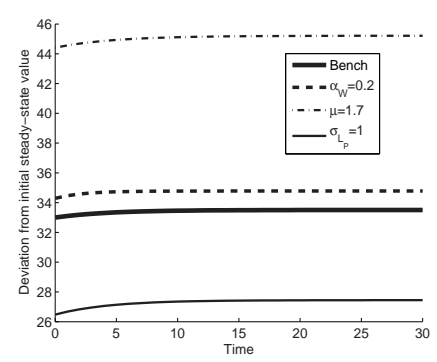

(b) Labor market tightness

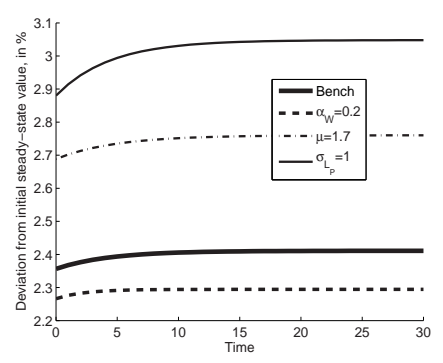

(d) Job seekers

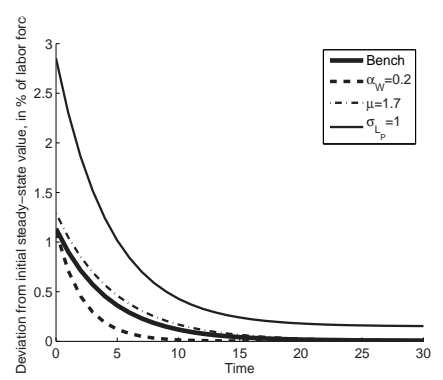

(f) Nash bargaining wage

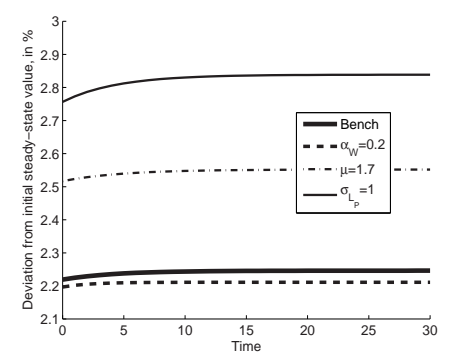

(h) Firm size

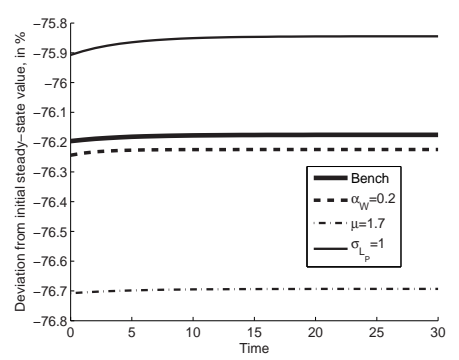

Figure 3: Computed transitional paths 


\section{A Data Description}

\section{A.1 Data for Empirical Analysis}

Our sample consists of a panel of 16 countries (Australia, Austria, Belgium, Canada, Denmark, Finland, France, Germany, Italy, Netherlands, New Zealand, Norway, Spain, Sweden, United Kingdom, United States) and covers the period 1985-2003, for two 1-digit ISIC-rev.3 industries (Electricity, gas and water supply, and Transport, communication and storage).

- Unemployment benefit replacement rate: Gross benefit replacement rates data which cover the period 1985-2003 with one observation every two years for each country. The OECD summary measure is defined as the average of the gross unemployment benefit replacement rates for two earnings levels, three family situations and three durations of unemployment. Source: OECD, Benefits and Wages Database.

- Price-cost margin: Computed as value added over total cost, both measured at current prices. Total cost is equal to the labor cost plus capital cost. To compute the price-cost margin, we use the following variables for:

1. Value added at current prices. Source: OECD STAN database.

2. Labor costs: Compensation of employees. Source: OECD STAN database.

3. Cost of capital. Long-term interest rates minus inflation rate, plus assumed depreciation of 15\%. Source: OECD Main Economic Indicators for long-term interest rates and consumer price index. Capital stocks have been calculated using the perpetual inventory method. Source: OECD STAN database.

- Tax wedge: This consists of the employment tax rate plus the direct tax rate. The employment tax rate is the ratio between employers' social security contributions and total compensation for employees net of employers' social security contributions. The direct tax is the ratio between the income tax plus employees' social security contributions and household current receipts. Source: Faggio and Nickell [2006].

- Employment protection legislation (EPL): This index, developed by the OECD, covers the period 1985-2003, and is designed as a multi-dimensional indicator of the strictness of legal protection against dismissals for permanent as well as temporary workers. The higher is EPL, the more restricted is a country's employment protection regulation. Source: OECD labour market statistics database.

- Collective bargaining coverage: The percentage of the employed labor force whose pay is determined by collective agreement. It ranges from 1985 to 2000, by 5-year period intervals. Source: Nickell et al. [2005] for 1985-1994 and OECD, Employment Outlook [2004] for 2000.

- Coordination of wage bargaining: This index describes the coordination level in the wage setting. It ranges from 1 to 5 , and the most coordinated countries have index equal to 5 . (5:economywide bargaining; 4:mixed industry and economy-wide bargaining; 3:industry bargaining; 2:mixed industry- and firm level bargaining; 1: fragmented bargaining, mostly at company level). It covers the period 1985-2003. Source: ICTWSS (Jelle Visser [2009]).

- Product market regulation (PMR): To capture the intensity of regulation over time, we use the time-series regulatory indicators in product market provided by OECD for seven non manufacturing industries. These regulatory indicators are measured on a scale from 0 to 6 . The PMR indicators which are used to estimate the relationship (57) have been chosen because they are available over the whole period 1985-2003 for the 16 OECD countries of our sample, unlike the economy-wide indicator which covers only three years $(1998,2003,2008)$. One drawback is that the PMR indicator covers only seven non-manufacturing industries (Airlines, Telecoms, Electricity, Gas, Post, Rail, Road). Since data for Gross fixed capital formation, necessary to calculate price-cot margins, are not available at such disaggregated level, we have decided to aggregate up from 2-digit to the following 1-digit ISIC-rev.3 industries: Electricity, gas and water supply, and Transport, communication and storage. Source: Conway, De Rosa, Nicoletti, and Steiner [2006].

- Change in sectoral inflation: Change in growth of the sectoral value added deflators. It covers the period 1985-2003. Source: KLEMS database [2009] and OECD STAN database (for NZL and NOR). 
Table 3: Descriptive Statistics (1985-2003)

\begin{tabular}{|l|cc|cc|}
\hline & \multicolumn{2}{|c|}{ mean } & \multicolumn{2}{c|}{ s.d. } \\
\hline Sector (ISIC-Rev.3) & $\mathrm{E}$ & $\mathrm{I}$ & $\mathrm{E}$ & $\mathrm{I}$ \\
Price-cost margin & 1.29 & 1.13 & 0.37 & 0.17 \\
Product market regulation & 4.13 & 4.06 & 1.25 & 1.41 \\
Cost of entry & 4.38 & 3.96 & 1.64 & 1.66 \\
Public ownership & 3.46 & 4.79 & 1.56 & 1.27 \\
$\Delta$ Inflation & -0.68 & 0.34 & 8.31 & 7.69 \\
Output gap & 0.00 & 0.00 & 0.05 & 0.03 \\
Tax wedge & 0.29 & 0.29 & 0.09 & 0.09 \\
Empl. protect. legisl. & 2.01 & 2.01 & 1.01 & 1.01 \\
Replacement rate & 29.77 & 29.77 & 13.04 & 13.04 \\
Bargaining coverage & 71.94 & 71.94 & 24.31 & 24.31 \\
Coordination & 3.01 & 3.01 & 1.36 & 1.36 \\
\hline
\end{tabular}

Notes: E: Electricity, gas and water supply; I: Transport, storage and communications.

Table 4: Data to Calibrate the Model (1995-1998)

\begin{tabular}{|l|ccc|c|}
\hline \multirow{2}{*}{ Countries } & \multicolumn{3}{|c|}{ Labor market } & Markup \\
\cline { 2 - 5 } & $u$ & $m$ & $\tau^{U}$ & $\mu$ \\
\hline AUT & 4.3 & n.a. & 65.1 & 1.08 \\
BEL & 9.5 & 0.10 & 65.3 & 1.30 \\
DNK & 5.8 & 0.26 & 98.9 & 1.26 \\
FIN & 13.5 & n.a. & 76.6 & 1.32 \\
FRA & 11.2 & 0.19 & 62.7 & 1.26 \\
DEU & 8.8 & 0.20 & 61.1 & 1.19 \\
GRE & 9.9 & 0.15 & 56.2 & 2.33 \\
IRL & 10.3 & 0.11 & 48.2 & 1.74 \\
ITA & 11.2 & 0.08 & 38.5 & 1.66 \\
LUX & 2.8 & 0.23 & $n . a$. & 1.55 \\
NDL & 5.8 & 0.13 & 73.9 & 1.29 \\
PRT & 6.5 & 0.11 & 72.1 & 1.32 \\
SPA & 17.0 & 0.11 & 77.2 & 1.37 \\
SWE & 9.1 & 0.58 & 55.5 & 1.34 \\
GBR & 7.3 & 0.30 & 52.3 & 1.34 \\
EU-15 & 10.0 & 0.20 & 64.6 & 1.42 \\
USA & 5.1 & 0.90 & 57.0 & 1.50 \\
\hline
\end{tabular}

Notes: $u$ is the harmonized unemployment rate; $m$ is the job finding $\overline{\text { rate; }} \tau^{U}$ is the unemployment benefit replacement rate; markup is the price-total cost margin. EU-15 represents (weighted) averages of the corresponding variables.

- Sectoral output gap: Deviation of sectoral output from trend. Sectoral value added in volume has been logged and detrended using an Hodrick-Prescott filter with the smoothing parameter set at 100. It covers the period 1985-2003. Source: KLEMS database [2009] and OECD STAN database (for NZL and NOR).

Summary statistics of the data used in the empirical analysis are displayed in Table 3.

\section{A.2 Data for Calibration}

We now describe the data employed to calibrate the model. We use two calibrations aimed at capturing the European and the U.S. labor and product markets. The data consists of 16 countries, including the fifteen European countries and the U.S. and are averages of the period 1995-1998. Our sample covers Manufacturing including energy and Business sector services. Summary statistics of the data used in the numerical analysis are displayed in Table 4.

- Unemployment rate denoted by $u$ : Unemployed (workers as share of the labor force), in \%. 
Average EU-15 unemployment rate shown in Table 4 is the working age population weighted sum of fifteen EU members' unemployment rates. Source: OECD Main Economic Indicators.

- Job finding rate denoted by $m$ : Monthly job finding rate come from Hobijn and Sahin [2007]. We compute the equivalent quarterly rate as $x+(1-x) x+(1-x)^{2} x$, where $x$ is the monthly job finding rate.

- Unemployment benefit replacement rate denoted by $\tau^{U}$ : Average of replacement rates for unemployed persons who earned $67 \%$ and $100 \%$ of average worker earnings at the time of losing job (first year of unemployment). Source: OECD, Benefits and Wages Database.

- Price-cost margin is denoted by $\mu$ calculated as the ratio value added over total cost. Further details of calculation are described above. Average EU-15 price-cost margin shown in Table 4 is the value added weighted sum of fifteen EU members' price-cost margins. Source: OECD STAN database. 


\section{References}

Andolfatto, D. (1996) Business Cycles and Labor-Market Search. American Economic Review 86(1), pp. 112-132.

Bassanini, Andrea and Romain Duval (2006) Employment Patterns in OECD Countries: Reassessing the Role of Policies and Institutions. OECD Economics Dept. Working Paper No. 486.

Bertrand and Kramarz (2002) Does Entry Regulation Hinder Job Creation? Evidence from the French Retail Industry. Quarterly Journal of Economics, 117, pp. 1369-1413.

Bilbiie, Florin, Fabio Ghironi and Marc Melitz (2010) Endogenous Entry, Product Variety and Business Cycles. NBER Working Paper No. 13646.

Blanchard, Olivier J., and Jordi Galí (2006) Labor Markets and Monetary Policy: A New Keynesian Model with Unemployment. Mimeo.

Blanchard, Olivier J., and Giancarlo Giavazzi (2003) Macroeconomic Effects of Regulation and Deregulation in Goods and Labor Markets. Quarterly Journal of Economics 118(3), pp. 879-907.

Boulhol, Herve (2010) Pro-competitive Effect of Trade and Non-decreasing Price-Cost Margins. Oxford Bulletin of Economics and Statistics, 72(3), pp. 326-356.

Cahuc, Pierre, Christian Gianella, Dominique Goux and Jacques Mairesse (1998) Equalizing Wage Differences and Bargaining Power. Discussion Paper INSEE No. 98-05.

Cahuc, Pierre, Fabien Postel-Vinay, and Jean-Marc Robin (2006) Wage Bargaining with On-theJob Search: Theory and Evidence. Econometrica, 74(2), pp. 323-364.

Conway, Paul, Donato De Rosa, Giuseppe Nicoletti, and Faye Steiner (2006), Regulation, competition, and productivity convergence OECD Economics Department Working Paper No. 509.

Crépon, Bruno, Rozenn Desplatz and Jacques Mairesse (1999) Estimating price cost margins, scale economies and workers' bargaining power at the firm level. Discussion Paper INSEE No. 99-17.

Dixit, Avinash and Joseph Stiglitz (1977) Monopolistic Competition and Optimum Product Diversity. American Economic Review, 67(3), pp. 297-308.

Driscoll ,John C. and Aart C. Kraay (1998) Consistent Covariance Matrix Estimation With Spatially Dependent Panel Data. The Review of Economics and Statistics, 80(4), pp. 549-560

Ebell, Monique, and Christian Haefke (2009) Product market deregulation and the US employment miracle. Review of Economic Dynamics, 12(3), pp. 479-504

European Union KLEMS (2009) Growth and Productivity Accounts.

Faggio, Giulia and Stephen Nickell (2006) Patterns of Work Across the OECD. CEP Discussion Paper, No. 730.

Fiorito, Riccardo and Giulio Zanella (2008) Labor Supply Elasticities: Can Micro Be Misleading for Macro? Quaderni del Diparmento de Economia Politica No. 547.

Gali, Jordi (1995) Product diversity, endogenous markups, and development traps. Journal of Monetary Economics, 36, pp. 39-63.

Greenwood, Jeremy, Zvi Hercowitz, and Gregory W. Huffman (1988) Investment, Capacity Utilization, and the Real Business Cycle. American Economic Review, 78, pp. 402-417.

Griffith, Rachel, Rupert Harrison and Gareth Macartney (2007) Product Market Reforms, Labour Market Institutions and Unemployment. Economic Journal 117, pp. 142-166.

Heijdra, Ben J., and Jenny E. Ligthart (2009) Labor Tax Reform, Unemployment and Search. International Tax and Public Finance, 16, pp. 82-104.

Hobijn, Bart and Aysegül Sahin (2007) Job-Finding and Separation Rates in the OECD. Federal Reserve Bank of New York Staff Reports No. 298.

Hosios, Arthur J. (1990) On the Efficiency of Matching and Related Models of Search and Unemployment. Review of Economic Studies, 57(2), pp. 279-98.

Jaimovich, Nir and Joseph Floetotto (2008) Firm Dynamics, Markup Variations and the Business Cycle. Journal of Monetary Economics, 55, pp. 1238-1252.

Kuroda, Sachiko and Isamu Yamamoto (2007) Estimating Frisch Labor Supply Elasticity in Japan. Imes Discussion Paper Series No. 2007-E-5.

Merz, M. (1995) Search in the Labor Market and the Real Business Cycle. Journal of Monetary Economics 36(2), pp. 269-300. 
Nekarda, Christopher J., and Valérie A. Ramey (2010) The Cyclical Behavior of the Price-Cost Markup. NBER Working Paper No. 15754.

Nickell Stephen, Nunziata Luca and Wolfgang Ochel (2005) Unemployment in the OECD since the 1960s. What do we know? Economic Journal, 115, pp. 1-27.

Nicoletti, Giuseppe and Scarpetta Stefano (2005) Product market reforms and employment in OECD countries. OECD Economics Department Working Paper No. 472.

OECD Employment Outlook (2004) Wage-setting Institutions and Outcomes (Chapter 3).

Petrongolo, Barbara and Christopher A. Pissarides. (2001) Looking Into the Black Box: A Survey of the Matching Function. Journal of Economic Literature, 39(2), pp. 390-431.

Roeger, Werner (1995) Can Imperfect Competition Explain the Difference between Primal and Dual Productivity Measures? Estimates for U.S. Manufacturing. Journal of Political Economy 103(2), pp. 316-330.

Shi, Shouyong, and Quan Wen (1999) Labor Market Search and the Dynamic Effects of Taxes and Subsidies. Journal of Monetary Economics, 43, 457-495.

Spector, David (2004) Competition and the capital-labor conflict. European Economic Review, 48, pp. 25-38.

Tybout, James R. (2003) Plant- and Firm-level Evidence on the 'New' Trade Theories. In: Choi, Kwan E. and James Harrigan (Ads.), Handbook of International Trade. Basil-Blackwell, Oxford.

Visser, Jelle (2009), ICTWSS Database, Database on Institutional Characteristics of Trade Unions, Wage Setting, State Intervention and Social Pacts in 34 countries between 1960 and 2007, Institute for Advanced Labour Studies, AIAS, University of Amsterdam, Amsterdam. http://www. uva-aias.net/207

Wu, Yangru, and Junxi Zhang (2000) Endogenous markups and the effects of income taxation: Theory and evidence from OECD countries. Journal of Public Economics, 7, pp. 383-406.

Yang, Xiaokai, and Ben J. Heijdra (1993) Monopolistic Competifion and Optimum Product Diversity: Comment. American Economic Review 83, pp. 295-301.

Zhang, Junxi (2007) Estimating the Effects of the Fiscal Policy in OECD Countries. Southern Economic Journal, 74(2), pp. 546-565. 